\title{
Strengthening resilience in Military Officer Cadets: A group-randomised controlled trial of coping and emotion regulatory self-reflection training
}

\author{
${ }^{* 1}$ Monique F. Crane, ${ }^{12}$ Danny Boga, ${ }^{1}$ Eyal Karin, ${ }^{3}$ Daniel F. Gucciardi, ${ }^{4}$ Frances \\ Rapport, ${ }^{4}$ Joanne Callen, and ${ }^{5}$ Laura Sinclair \\ ${ }^{1}$ Department of Psychology, Macquarie University \\ ${ }^{2} 1$ st Psychology Unit, Australian Defence Force \\ ${ }^{3}$ School of Physiotherapy and Exercise Science, Curtin University \\ ${ }^{4}$ Centre for Healthcare Resilience and Implementation Science Australian Institute of \\ Health Innovation, Macquarie University \\ ${ }^{5}$ Directorate of Strategic and Operational Mental Health, Commonwealth Department \\ of Defence
}

*Correspondence to:

Monique Crane

Department of Psychology, Building C3A, Macquarie University, North Ryde, NSW, 2109, Australia

E: Monique.crane@mq.edu.au

P: +61298508604

Crane, M.F., Boga, D., Karin, E., Gucciardi, D.F., Rapport, F., Callen, J., \& Sinclair, L. (2019). Strengthening resilience in military officer cadets: A group-randomised controlled trial of coping and emotion regulatory self-reflection training. Journal of Consulting and Clinical Psychology, 87, 125-140. doi: 10.1037/ccp0000356 


\begin{abstract}
Objective: This group-randomized control trial examined the efficacy of guided coping and emotion regulatory self-reflection as a means to strengthen resilience by testing the effects of the training on anxiety and depression symptoms and perceived stressor frequency after an intensive stressor period.
\end{abstract}

Method: The sample was 226 Officer Cadets training at the Royal Military College, Australia. Cadets were randomized by platoon to the self-reflection $(n=130)$ or coping skills training $(n=96)$. Surveys occurred at three time points: baseline, immediately following the final reflective session (four weeks post-baseline), and longer-term follow-up (three months postinitial follow-up).

Results: There were no significant baseline differences in demographic or outcome variables between the intervention groups. On average, Cadets commenced the resilience training with mild depression and anxiety symptoms. Analyses were conducted at the individual-level after exploring group-level effects. No between-group differences were observed at initial followup. At longer-term follow-up, improvements in mental health outcomes were observed for the self-reflection group, compared to the coping skills group, on depression (Cohen's $d=0.55$; $95 \%$ CI $[0.24,0.86]$ ), anxiety symptoms (Cohen's $d=0.69 ; 95 \%$ CI $[0.37,1.00]$ ), and perceived stressor frequency (Cohen's $d=0.46$; 95\% CI [0.15, 0.77]). Longitudinal models demonstrated a time by condition interaction for depression and anxiety, but there was only an effect of condition for perceived stressor frequency. Mediation analyses supported an indirect effect of the intervention on both anxiety and depression via perceived stressor frequency.

Conclusions: Findings provide initial support for the use of guided self-reflection as an alternative to coping skills approaches to resilience training.

Keywords: mental health; military; stressors; metacognition; soldiers

Statement of significance. This study provides evidence for the use of guided coping selfreflection as an alternative resilience training approach that can be administered in large group 
3 RUNNING HEADER: STRENGTHENING RESILIENCE IN OFFICER CADETS

settings. Beyond the training implications, the effective use of self-reflection also speaks to the potential for individuals to develop their personalized resilience strategy as they encounter daily challenges. 


\section{Strengthening resilience in Military Officer Cadets: A group-randomizeed controlled trial of coping and emotion regulatory self-reflection training}

The varying levels of stressors and adversity inherent in military service (e.g., Ryan et al., 2007), underscores the importance of ensuring personnel have the capacities to increase the probability of resilience despite occupational risk. Organizations, including the Australian Defence Force (ADF), have endeavoured to develop effective and sustainable resiliencestrengthening programs to reduce the risk of mental health issues (e.g., depression and anxiety) in personnel (Adler, Bliese, McGurk, Hoge, \& Castro, 2009; Cacioppo et al., 2015; Cohn, Crane, \& Hodson, 2011; Cohn \& Pakenham, 2008; Cornum, Matthews, \& Seligman, 2011). In a recent review, psychological resilience was defined as "a good mental health outcome following an adverse life event or a period of difficult life circumstances" (Kalisch et al., 2017, p. 786). Consistent with this definition, resilience training aims to prevent the onset of psychological distress in those exposed to risk, such as military personnel (Robertson, Cooper, Sarkar, \& Curran, 2015). Preventative strategies, such as resilience training, help to ensure that as far as possible, personnel are equipped with the psychological skills necessary to enable them to bounce-back from, or withstand the effects of (Fletcher \& Sarkar, 2016), a diverse range of stressor experiences they may encounter on-the-job. Our research tests the application of a new approach to resilience training in the military training context using a grouprandomized controlled trial.

\section{Approaches to resilience training and their effectiveness}

Most previous examples of resilience training use a combination of cognitivebehavioral strategies (e.g., Arnetz, Nevedal, Lumley, Backman, \& Lublin, 2009; Cohn \& Pakenham, 2008; Waite \& Richardson, 2003), psycho-education and guided practice of the techniques, and the development of protective factors (e.g., social resources, positive outlook, and adaptive cognitive strategies) (see Vanhove, Herian, Perez, Harms, \& Lester, 2016 for review). These approaches are adapted from those used in therapeutic contexts including: mindfulness and loving-kindness meditation (e.g., Burton, Pakenham, \& Brown, 2010; 
Jennings et al., 2013; Pidgeon, Ford, \& Klassen, 2016), thought reappraisal and self-talk (e.g., Cohn \& Pakenham, 2008), building positive and supportive relationships (e.g., Cacioppo et al. 2015; Cohn \& Pakenham, 2008; Millear, Liossis, Shochet, Biggs, \& Donald, 2008) and selfregulation of stress responses (e.g., Cohn \& Pakenham, 2008; McCraty \& Atkinson, 2012). These skill development approaches focus on shaping knowledge by providing information about commonly adaptive skills and the effect of certain thoughts or behaviors on mental or physical performance (e.g., Adler, Williams, McGurk, Moss, \& Bliese, 2015; Arnetz et al., 2009). These skills are then practiced/rehearsed (e.g., Arnet et al., 2009; Millear et al., 2008) with or without the receipt of feedback.

Effectiveness of previous interventions. Meta-analyses examining the effectiveness of group-based coping skills training have demonstrated moderate to large effects on mental health and wellbeing outcome measures (e.g., Leppin et al., 2014; Robertson, et al. 2015, Vanhove et al., 2016). Of the studies examined, some demonstrated no significant change in mental health outcomes at initial or longer-term follow-up (e.g., Pidgeon et al., 2014; Waite \& Richardson, 2003) and others large effects compared to a control group (Arnetz et al, 2009; McCarty \& Atkinson, 2012). Thus, trials of different programs using a coping skills development framework demonstrate inconsistent capacity to elicit changes in wellbeing indices. Moreover, the effects of training on mental health outcomes can be inconsistent even among trials of the same program (e.g., Liossis, Shochet, Millear, \& Biggs, 2009; Millear et al., 2008). An additional challenge of resilience training has been achieving sustained effects over time. A meta-analysis of 37 studies found that these resilience programs yielded significant, albeit small initial effects that tended to reduce at longer-term follow-up (>1 month) (Vanhove et al., 2015). However, programs targeting individuals at-risk (“experiencing stress or lacking core protective factors" Vanhove et. al., 2016, p. 278) demonstrated an increased efficacy over time. A further meta-analysis of resilience training trials indicated low confidence in the results given sources of bias (e.g., blinding of participants) (Leppin et al., 2014). 
Practical obstacles of training resilience. Irrespective of available evidence for the efficacy of these programs, such training approaches are characterized by a variety of practical constraints, particularly in the military context. Training often involves small groups (8-14 people) and long periods of training, at times 30 hours long (e.g., Burton et al., 2010; Jennings et al., 2013; Millear et. al., 2008). In organizational settings with a large and geographically dispersed workforce, such training can be expensive and impractical. The intervention developed in this paper is one that can be readily administered to large groups and requires a relatively short administration time (i.e., 1 hour and 45 minutes).

\section{Resilience training in the military}

Historically, resilience training trials within the military have tended to yield small or no discernible effect on mental health outcomes that reduce overtime. The study most similar in context to the present trial was a group-RCT conducted in basic-training Army soldiers (Cohn \& Pakenham, 2008). The intervention consisted of two 40-minute sessions of psychoeducation, cognitive restructuring and positive behavioral strategies (e.g., support seeking) tailored to the basic-training setting. Recruits were followed-up at two-time points: immediately post the training and follow-up (approximately 2-weeks later). Psychological distress was assessed with the General Health Questionnaire (GHQ-12) and wellbeing was measured using the Positive States of Mind Scale. Findings demonstrated reductions in psychological distress symptoms and increased positive states of mind in the resilience training condition, compared to an active control group. However, the between-group effect sizes were small particularly for psychological distress symptoms (GHQ-12; $d=0.24$; Cohn \& Pakenham, 2008).

A resilience program was also later introduced to US Army basic training based on the brief intervention developed by Cohn and Pakenham (2008). The two-hour training focused on cognitive-behavioral skill development involving developing an understanding of common stress reactions, distinguishing between controllable and uncontrollable stressors, anxiety reduction techniques, and the development of flexible coping (Adler et al., 2015). The group- 
randomized controlled trial demonstrated no significant effects for mental health outcomes anxiety and depression between the intervention and control group over time, but there was some evidence that anxiety symptoms reduced faster after the training in the intervention condition than in the active control.

The United States Army also introduced the Comprehensive Soldier Fitness program (renamed Comprehensive Soldier and Family Fitness CSF2) to enhance solider resilience (Cornum, et al., 2011). Soldiers receive training in four core modules: (1) introduction to resilience, (2) cognitive-behavioral skills training, (3) identification of character strengths (e.g., Park, Peterson, \& Seligman, 2004), and (4) strengthening relationships via teaching of communication techniques (for descriptions of CSF2 see: Cornum et al., 2011; Harms, Herian, Krasikova, Vanhove, \& Lester, 2013). Thus, the CSF2 involves the direct teaching of coping and emotion regulatory capacities (e.g., relaxation) and skills (e.g., communication skills) to enable the enhancement of personal resources (e.g., supportive relationships and adaptive beliefs (e.g., optimism). The results of empirical trials of the CSF2 were not published in the peer-review literature, but industry reports demonstrate that the, CSF2 appeared to have no direct effect on mental health outcomes. Mediation analysis demonstrated that CSF2 was able to reduce mental health symptoms via optimism and adaptability, but the indirect effects were generally small (Harms et al., 2013). Across these military trials, it appears harder to attain effects on mental health outcomes comparable to those in the civilian setting.

In the current study, we implemented an approach to resilience training that differs from past work. Rather than training a range of discrete cognitive or behavioral skills, our approach involved the use of a single metacognitive skill: coping and emotion regulatory self-reflection. The purpose of this study was to test whether this new approach to resilience training assists military personnel to withstand or bounce back after a period of intense training stressors. This is the first trial of guided coping and emotion regulatory self-reflection for the purpose of strengthening resilience. 
Self-reflection is a metacognitive approach to the analysis of life experiences. The definition of self-reflection we apply here reflects the dominant understanding within the literature. Self-reflection is the development of self-awareness and enhanced understanding based on the active and persistent examination of one's existing knowledge, approaches and beliefs (Boud, Keogh, \& Walker, 1985; Grant, Franklin, \& Langford, 2002). Coping and emotion regulatory self-reflection is characterized by targeted examination of one's existing coping and emotion regulatory strategies and approaches in relation to stressor events, rather than a reflection on one's broader knowledge, beliefs, and approaches. In this context, reflection involves the deliberate and purposeful act of thinking; however, what people choose to reflect on is critical if reflection is to be effective for the development of resilience. We suggest that coping and emotion regulatory self-reflection needs to be multifaceted in nature and involve balancing self-awareness, self-evaluation of one's coping and emotion regulatory response, and constructive adaption. Specifically, these aspects include an awareness of emotional, behavioral, cognitive and physiological responses to stressors, a critical evaluation of the efficacy of the coping and emotion regulatory response, consideration of what can be learnt or developed through these events, and how to adapt better in the future. However, this approach does not employ the direct training of coping skills, rather self-reflection enables the ongoing evolution of coping strategies for problem solving, the capacity to reflect on and evaluate these strategies, and enables change to be brought about.

Coping and emotion regulatory self-reflection was selected for use as a resilience training strategy by drawing together several lines of research and theory. The first relates to theory and research in the area of resilience suggesting that stressor exposures are necessary in the strengthening of resilience (e.g., Moore, Young, Freeman \& Sarkar, 2018; Richardson, 2002; Seery, Holman, \& Silver, 2010). Our approach views psychological resilience as a learning process that can be engendered through the experience of life-stressors (e.g., exams) or adversity (e.g., divorce, financial strain) and self-reflection on one's coping and emotion regulatory approach (Crane, Searle, Kangas, \& Nwiran, 2018). In the last decade, accumulating 
research suggests that some level of exposure to adversity (i.e., 2-4 adverse or traumatic events) appears to predict greater resilience, compared to no exposure or more than four events (Seery et al., 2010). Other work has identified the importance of adversity for athlete performance (e.g., see Sarkar \& Fletcher, 2017 for review; Moore et al., 2017). The implication of this research is that resilience is developed from stressor exposures throughout life as part of an experiential learning process.

Like any experience, exposure to stressors can yield both adaptive and maladaptive behaviors and practices. As noted by Sarkar and Fletcher (2017), the experience of adversity alone is insufficient to yield positive outcomes. Engagement in constructive self-reflection, however, appears to play a useful role in learning from experience and in the learning process (Cranton, 1994; Sarkar \& Fletcher, 2014). Approaches to adult transformational learning have proposed that critical self-reflection processes may be triggered by 'disorientating' events in one's life prompting a revision of assumptions, current ways of interpreting the world and one's approaches through critical self-reflection (Merzirow, 1990, 1991). Although self-reflection has been largely applied to the development of academic knowledge, professional values and skills (e.g., Lew \& Schmidt, 2011), there is increasing consideration for the role self-reflection may play in the emergence of resilience. Recent qualitative research has specifically identified the role of learning through experience and reflection in resilience (Sarkar \& Fletcher, 2014). Tedeschi and Calhoun (1996) proposed that meaning and perceived benefit can be derived from traumatic events in different life domains resulting from a process of reflective thinking (Angel, 2016) that leads to increased future resilience (Angel, 2016; Tedeschi, 2011). Moreover, theoretical work has highlighted the potential for the cognitive processes involved in normal maturation (that may include self-reflection) to be engaged in the emergence of post-traumatic growth (Eve \& Kangas, 2015).

A recent model, on which our intervention is based, articulates how the specific coping and emotion regulatory self-reflective process works to strengthen the capacity for resilience (Crane, et al., 2018). In this model, the focus of self-reflection is on dispassionate self- 
exploration and self-development of one's coping and emotion regulatory response in relation to stressor events. Via the self-reflection process, the individual is encouraged to examine their initial coping responses critically in order to develop new or enhanced understandings and adaptations allowing the emergence of a flexible coping and emotion regulatory system. A more sophisticated and flexible coping and emotion regulatory repertoire emerges as the individual refines their personal model of resilience facilitating downstream resilient outcomes during times of stress and adversity.

\section{Self-reflective writing versus expressive writing}

Expressive writing paradigms focus on the expression of emotions and thoughts emerging because of recent stressor events. Expressive writing paradigms have demonstrated effectiveness for reducing stress, ruminative thought, post-traumatic stress, and depressive symptoms (e.g., Baikie, Geerligs, \& Wilhelm, 2011; Gortner, Rude, \& Pennebaker, 2006). Our reflective writing paradigm differences from expressive writing in three core ways. First, expressive writing does not guide writers to consider how the experience of recent stressors may be an opportunity to develop their coping capacity (i.e., stress-as-enhancing; Jamieson, Crum, Goyer, Marotta, \& Akinola, 2018). Second, coping and emotion regulatory reflection engages reflectors in a process of self-evaluation with respect to the usefulness of coping or emotion regulatory strategies for allowing adherence to personal values or value-based goals (e.g., goal monitoring Harkin et. al., 2016). Third, reflectors are also asked to consider how strategies and resources could be extended or refined to allow an expanded and flexible coping repertoire, facilitating resilience in the future (Bonanno \& Burton, 2013; Bonanno, PatHorenczyk, \& Noll, 2011). Reflection is directed to the self-exploration of coping and emotion regulatory strategies in order to allow broadening of the strategy repertoire.

\section{The Present Study}

This paper tests the efficacy of self-reflection training (SRT) as compared to coping skill training (CST), which is treatment as usual. A recent meta-analysis of the resilience training literature proposed that the accurate assessment of resilience training would require a 
significant challenge or adversity during the study period (Joyce et al., 2017). Thus, we chose a highly stressful officer training environment with a discrete stressor period as the context for this research. The approach to intervention testing is best considered a "during stressor exposure" framework (p. 97; Chmitorz et al., 2018).

Symptoms of anxiety, depression, and perceived stressor frequency were selected as our primary outcomes for three reasons. First, reducing symptoms of depression and anxiety in Cadets is a desired organizational outcome. Officer training is intended to prepare Army Officers for employment in war-like environments and is by necessity incredibly stressful and at times a distressing experience. Although the ADF selects people who demonstrate the potential to cope with the demands of military training, combat conditions often exceed the stressors generally experienced by the general population. As such, there was a perceived need, by military command, to institutionalize resilience training to support the Cadets through the rigors of training and enable them to be better equipped to perform their duties under complex, dangerous, and time-pressured conditions. Initial stages of military training represent a key development period for soldiers and officers, and the stress associated with training contributes to trainees being discharged as a result of psychological difficulties (Cohn \& Pakenham, 2008; Johnsen, Laberg, \& Eid, 1998). Second, previous work has demonstrated that anxiety and depression measures have had the largest and consistent effects in civilian trials (Robertson et al., 2015). Third, we measured perceived stressor frequency because we anticipated that stressor events would be re-appraised as learning or growth opportunities and characterized less frequently as difficult stressor events.

We anticipated that the changes in these primary outcome measures would be evident between initial follow-up and longer-term follow-up because this period is when training stressors temporarily subside after reaching a crescendo where Cadets will, on-average, have experienced a high level of stress. Formally stated the hypothesis was: 
The SRT group would demonstrate a greater decline in perceived stressor frequency (H1), anxiety (H2), and depression symptoms (H3) between initial follow-up to longer-term follow-up, compared to the CST group.

\section{Method}

\section{Research context}

The Royal Military College (RMC) is designed to train future Army Officers and occurs in three stages over a period of 18 months. The initial stage (third-class) is six months long, the second stage (second-class) is an additional six months and the final stage (first-class) is the final six months prior to graduation. Training involves several aspects including academic work, physical training, field exercises, and on-going assessment of these elements. Training is physically, emotionally, and academically demanding. The present study was conducted in second-class, which is the steepest learning period of the three classes. It is the formative period and involves a high pace of academic work involving new concepts and high intensity physical training.

During second-class, the more challenging activities involve the application of Cadets' learned skills in the field in simulated ground-warfare. Cadets are assessed on their capacity to lead their peers. During field exercises, Cadets sleep in self-dug pits with only the resources they carry in their packs. Most arduous of these field exercises involves a period (6-days) of food and sleep deprivation, whilst the Cadets are required to respond to physical, moral, and tactical demands. Cadets are constantly evaluated by Directing Staff for their leadership skills, operational skills (e.g., navigation), and character. This stage of the training process was considered the ideal context for evaluating the SRT. The training demands of second-class RMC increase in intensity over the initial five months from commencement and reach a crescendo by the end of the fifth month as part of field exercises. Thereafter, Cadets are given a short period of recovery. The timing of our surveys was designed to capture the rise and fall of stressor demands. 
The SRT program is described with reference to the behavior-change interventions checklist (Borek, Abraham, Smith, Greaves, \& Tarrant, 2015) and the behavior change technique taxonomy (Michie et al., 2013) to elucidate the mechanisms of change employed in the SRT. The application of coping self-reflection in strengthening resilience was theoretically derived (Crane, et al., 2018). We drew from various areas of scholarship to propose that strengthening resilience as a consequence of exposure to stressors and adversity is dependent on the capacity to critically and constructively reflect on one's coping and emotion regulatory attempts as some strategies are of greater benefit than others in particular contexts (Britt, Crane, Hodson, \& Adler, 2016). Five reflective practices are encouraged as part of the training in order to strengthen resilience: (1) awareness of one's emotional, physical, behavioral and cognitive responses to triggering events, (2) awareness of values and value-based goals in relation to the situation, (3) awareness of strategies applied to address the situation, (4) evaluation of strategy effectiveness in relation to values and goals, and (5) constructive adaptations of strategies to promote improvements in future strategies. Questions were generated intended to encourage the above five practices to guide the self-reflection (see Table S1). The behavior change techniques employed as described by Michie, et al., (2013) are also provided in Table S1. Question phrasing and the language used in the initial briefing session was developed in collaboration with Army psychologists and the lead second-class instructor from RMC over a 12-month period.

Initially, the entire group of Cadets in the SRT group received a single 30-minute brief about the training program in a large lecture theatre. This initial brief covered: (1) understanding how the experience of stressors can strengthen resilience, tolerance and performance (i.e., stress-as-enhancing mindset; Jamieson, et al., 2018), (2) understanding that resilience is malleable and can be developed over time (i.e., growth mindset; Yeager \& Dweck, 2012), (3) how reflecting appropriately on stressors and setbacks in one's life can enhance resilience, (4) identification of leadership values in relation to coping under pressure, and (5) how to complete the questions in the workbook. In order to elicit leadership values Cadets 
undertake a writing task during the 30-minute brief where they are asked to consider a leader they admire and the types of characteristics that they find the most admirable in that leader. Cadets are then asked to define these characteristics in terms of core values (e.g., compassion). Cadets then identify behaviors consistent with these values that they would ideally demonstrate under pressure. We inform Cadets that these value-based behaviors are aspirational and could be seen as something that they are training toward. It this way, the stressors Cadets face in training are re-framed as opportunities to develop valued leadership skills. Relevant values provide context to coping and emotion regulation and represent a standard by which to evaluate one's stressor response and an introspective process for attaining feedback.

Following the initial brief, Cadets completed a 15-minute guided self-reflection writing task in a workbook each week for five weeks. The guided self-reflection was intended to help the Cadets reflect on their stressor experiences, develop an awareness of their approaches to coping and emotion regulation, consider the effectiveness of these strategies, and improve the application of coping for the future. The workbook required Cadets to address the same series of reflective questions each week. There was no additional input from the administrator of the workbooks except to assist Cadets on how to respond to the reflective questions themselves when requested.

\section{Self-reflective question development}

The reflective questions were developed via a review of the empirical self-reflection literature as applied to learning (e.g., Lew \& Schmidt, 2011), the scholarship on brief-solution focused therapy (e.g., Bannick, 2010), theoretical work on transformational learning (Cranton, 1994; Mezirow, 2003; Mezirow, 1998), and empirical work on after-event reviews (e.g., Ellis \& Davidi, 2005). A set of questions were trialled initially in a small cohort of organizational psychology post-graduate masters students $(N=29)$. Participants were 29 post-graduate students (17.2\% male; $58.6 \%$ female; $24.1 \%$ not reported) undergoing an intense period of coursework, assessments, exams and evaluated practice. Participants completed five weekly written coping self-reflection workbooks focused on their efforts to cope with these training stressors. These 
workbooks were collected and two independent raters examined the capacity of these selfreflection questions to elicit the desired reflection content. Questions were revised based on the insights drawn from this initial pilot work. For example, it was evident that respondents were unbalanced in the critique of their coping. Most participants provided positive aspects of coping, but excluded an articulation of the negative aspects. Given previous work on afterevent reviews (Ellis \& Davidi, 2005), it was important that participants acknowledge both successes and failures. Thus, we modified the questions so that participants rated the effectiveness of their coping on a rating scale (see Table S1). Then if their coping strategy was less than completely effective, the participants were directed to suggest why their coping was not completely effective.

\section{Participants and Design}

To test the viability of coping self-reflection as a resilience training strategy, we conducted a randomized by platoon controlled trial within the military training context, in particular Cadet training. Two-hundred and twenty-six Cadets commenced second-class at RMC in January 2017. Of these 226 Cadets, 215 (95.13\%) consented to being involved in the SRT evaluation ( $16.9 \%$ females; $83.1 \%$ males). This rate of initial consent is comparable to other resilience training evaluations conducted within the Army (e.g., Cacioppo, et al., 2015). On average, the Cadets were 22 years old ( $S D=3.86$; ranging from 18 to 42 years), and had served in the Army for an average of 2.4 years ( $S D=1.74$; ranging from 6 months to 11 years). Fifty-one per cent of Cadets were completing a degree at the Australian Defence Force Academy ( $n=102)$ and $37 \%$ were new to the Australian Defence Force $(n=77)$. A small number of Cadets $(6 \%, n=12)$ from international militaries (e.g., New Zealand) were also completing second-class at RMC.

Assignment to one of the two intervention conditions was randomized by platoon, which is a common practice in military training evaluations in order to avoid crosscontamination of training content (Adler et al., 2009; Cacioppo, et al., 2015). RMC instructors 
assigned the seven platoons to two groups and were unaware which of the two-groups would receive which training. Similar to the randomization method used by Adler et al. (2009), instructors were asked to ensure that there were no differences between the groups in terms of gender composition, ability or other dimensions when assigning the platoons. Given the training context, Cadets are not allocated to unit types (e.g., infantry, artillery) because these decisions occur after the completion of RMC training. In this way, there are no ostensible differences in platoons by design. Three platoons received CST $(n=96)$, whereas the remaining four platoons received SRT $(n=130)$. Given that intervention allocation was by platoon, there was continuity of intervention membership throughout the program. There were no exclusion criteria for participation in the study.

The CST was based on the work of Cohn and Pakenham (2008) who developed and trialled a cognitive and behavioral based resilience program in the Australian basic training setting (see Cohn, Crane, \& Hodson, 2011 for a detailed description). In the 30-minute CST session, Cadets were introduced to the concept of resilience, arousal reduction techniques (deep breathing, grounding), and distorted thinking styles that may impair their performance and resilience. When mapped against a behavior change techniques taxonomy (Michie et al., 2013), the CST program uses elements of the broad categories of shaping knowledge, regulation, and self-belief.

Two Army psychologists with a minimum 2-years of experience in military resilience training delivered the initial 30-minute training session for the CST and SRT programs. The trainer for the SRT received 1-day of training with the lead investigator involving the following: (1) understanding the philosophy of SRT, (2) understanding the self-reflective process as applied to coping, (3) observing the training delivery, and (4) practice delivery with feedback. The lead investigator who is a registered psychologist facilitated the guided selfreflection. In all other respects, Cadets received the same training experience at RMC.

During the initial briefing, participants were blinded to their experimental condition. Both training groups were told they were receiving resilience training and that we wished to 
examine how each program performed relative to the other and that there were no expectations about which training would be better.

Cadets were asked to complete the survey instrument on three occasions: (1) at baseline (prior to the intervention), immediately post-training, and at long-term follow-up. The longterm follow-up survey occurred just over three months from the completion of the SRT. The baseline survey was conducted on 23rd January 2017, the initial post-intervention survey on the 25th of February 2017, and a long-term follow-up survey on 7th June 2017. At longer-term follow-up, Cadets may also have withdrawn from second class due to physical injury, poor performance or other personal reasons. All surveys were completed using pen and paper. The flowchart for the training trial is provided in Figure 1.

\section{[FIGURE 1 HERE]}

\section{Procedure}

The study procedure was reviewed and approved by the ADF Human Research Ethics Committee (protocol number: 839-16) and [concealed for peer review] Human Research Ethics Committee (protocol number: 5201600964). The SRT and CST interventions were delivered at the same time in separate rooms by two Army Psychologists. Both the SRT and CST interventions were initially in a PowerPoint format. Thereafter, Cadets in the CST group received no further training. However, the SRT group Cadets met weekly for five weeks, for 15-minutes, to complete a self-reflection activity. During this same period, the CST group had free time. On the fifth week, Cadets in both intervention groups completed the initial followup survey. Over three-months later Cadets in both intervention groups were asked to complete the longer-term follow-up survey. All surveys were completed in a large hall at the RMC campus. However, whether or not individual Cadets participated in the study was unknown to RMC staff or researchers.

\section{Primary Outcomes}

Perceived frequency of training stressors. This measure is intended to capture the perceived stressor frequency of the stressors relevant to the RMC training context. The list was 
created in collaboration with an Army psychologist and RMC training instructor familiar with the training stressors at RMC. There were 23 items in this list (e.g., "A lot of academic work", "uncertainty about aspects of my training", "time pressure to get tasks done") and Cadets were asked: "How often did this stressor occur in the past week?" which they indicated their response with 0 (No days) to 5 (Everyday). The total stressor frequency was calculated by adding the responses to the 23 items, where higher scores indicated more occurrence.

Measure of depression symptoms. The Patient Health Questionnaire -8 items (PHQ8) was used to examine the presence of current depression symptoms and their severity in Cadets at all three time points (Kroenke et al., 2009). Participants indicated how often they had been bothered by the problems (e.g., "Little interest or pleasure in doing things", "Feeling down, depressed, or hopeless"), over the last two weeks, using a 4-points scale from 0 (Not at all) to 3 (Nearly everyday). A total score was calculated as the sum of these 8-items. Higher scores indicate greater depression symptom severity, and a total score of $\geq 10$ is indicative of a major depressive disorder (Kroenke et al., 2009). The PHQ-8 has been found to have good psychometric properties (Kroenke et al., 2009) and has been used successfully in military populations (Wells, Horton, LeardMann, Jacobson, \& Boyko, 2013). The eight-items demonstrated satisfactory internal reliability at all three time points $\left(\alpha_{\mathrm{B}}=.81, \alpha_{\mathrm{IF}}=.83, \alpha_{\mathrm{LF}}=.81\right)$.

Measure of anxiety symptoms. The Generalised Anxiety Disorder 7-Item (GAD-7) Questionnaire contains 7-items designed to measure symptoms of anxiety and anxiety severity. The GAD-7 has been demonstrated to have good psychometric properties (Loẅe, et al., 2008). Example items are: "Trouble relaxing" and "Not being able to stop or control worrying". Cadets indicated how often they have been bothered by the problems, over the last two weeks, using a 4-points scale from 0 (Not at all) to 3 (Nearly everyday). A total score was calculated by adding the responses to the 7 items, higher scores indicating greater anxiety severity. The measure demonstrated satisfactory internal reliability at all three time points $\left(\alpha_{\mathrm{B}}=.85, \alpha_{\mathrm{IF}}=.90\right.$, $\left.\alpha_{\mathrm{LF}}=.91\right)$.

\section{Secondary Measures}


Secondary measures were included in the study, but not examined in this paper. These measures focus on the presence or absence of relatively stable belief systems or personal qualities anticipated to predict training engagement and self-reflection quality, and not anticipated to change because of the training. The measures were: self-efficacy (Lindberg, Wincent, \& Örtqvist, 2013), dispositional hope (Snyder, 1995), and optimism (Scheier, Carver, \& Bridges, 1994). Such measures will be analysed as part of an analysis of secondary outcomes reflecting distinct research questions.

\section{Analysis Strategy}

The longitudinal changes between the groups were tested with the use generalized estimation equation (GEE) models. GEE emphasizes the measurement of group change over time whilst accounting for within-subject variance over time (Hubbard, et al., 2010). All models included an unstructured working correlation matrix to account for the unique variance structure that can occur between pre-treatment, initial follow-up and longer term follow-up. Change over time was modelled with a categorical time coefficient that enables the measurement of nonlinear change in symptoms over time. The models of depression and anxiety specified a log link function, coupled with gamma scale to account for the positive skewness of scores, observed within each of the time points and within both intervention conditions. Pairwise comparisons were also derived from the marginal models, seeking to test specific interaction effects, such as specific comparison between intervention conditions within specific time points. Estimates such as Cohens $d$ were calculated to convey the magnitude of both within and between-subjects effects. Cohen's $d$ was calculated based on estimated marginal means from the longitudinal models. In this way, the longitudinal characteristics of the data were reflected in the calculation of effect sizes. All analyses were conducted using SPSS version 22.

We conducted a generalized linear mixed model (GLMM) to determine whether platoon membership explained a significant amount of variance in the outcome variables. An initial model with no predictors explored the unique variance explained by platoon. For all 
three predictors, platoon explained non-significantly between $0.09 \%$ and $3.6 \%$ of the variance. These low values indicating that little of the variance was associated with platoon membership.

We also explored the mediating role of perceived stressor frequency at initial followup in the relationship between intervention group and anxiety and depression symptoms at longer-term follow-up via Hayes' bootstrapping approach using the PROCESS macro (Hayes, 2013). Two mediation analyses were performed. The first examined the mediating role of initial follow-up perceived stressor frequency on the relationship between intervention group (SRT vs CST) and long-term follow-up anxiety symptoms. The second tested the mediating role of initial follow-up perceived stressor frequency on the relationship between intervention group (SRT vs CST) and longer-term follow-up depression symptoms. Both models controlled for baseline measures.

To account for missing cases, and consistent with expert recommendation (Little \& Rubin, 2014), evidence for non-ignorable missing data were tested. This step was operationalized by considering the ability of any demographical, symptom, or experimental variable to predict follow-up missing cases likelihood. Using a logistic regression and model building strategy outlined by Harrell (2015) with all outcome, predictor and demographic variables initially included in the model. Variables that did not predict follow-up missing cases status were removed in a stepwise manner. Analyses identified that being in the SRT group, rather than the CST, was the only variable that predicted missingness post-intervention. This difference in missingness between the groups is likely to reflect the greater time commitment required of the SRT group, than the CST group. Given this result, missing cases where considered to be missing conditionally (conditional MAR assumptions). To account for this non-ignorable pattern of missingness, replacement estimates for missing cases were conditionally imputed through a longitudinal GEE model procedure (Karin, Dear, Heller, Crane, \& Titov, 2018), adjusting for an individual's baseline, intervention group, time point, and a time by intervention group. 
To determine the statistical power of the longitudinal analysis a post hoc power analysis was conducted. A post hoc analysis strategy was selected given that little of the necessary apriori statistical information is available about the effectiveness of such interventions within military populations (e.g. symptom change $(\Delta)$, symptom variance and within subjects effects). Instead, an achieved GEE power analysis was conducted using the "longpower" in $\mathrm{R}$ (Donohue, Gamst, Edland, \& Donohue, 2013). In this analysis, the CST condition was used as the standard group (care as usual) used to identify the remaining needed variance components. These power analyses enabled the calculation of the minimally detectable symptom difference between the SRT and CST groups which would still be considered powered, when power assumptions are set at 0.80 and an alpha significance level of 0.05 . These minimally detectable differences were used to calculate non-inferiority margins, which are between group differences that are both sufficiently powered and clinically meaningful (Greene, Morland, Durkalski, \& Frueh, 2008).

Consistent with the interpretation of non-inferiority trials (Greene et al., 2008), if the $95 \%$ confidence interval of the mean difference between the groups is overlapping with a noninferiority margin, then SRT can be concluded to be equivalent to the standard CST group (care as usual). If the $95 \%$ confidence interval of the mean difference between interventions exceeds the non-inferiority margin, then the SRT is concluded to be inferior (e.g. higher outcome symptoms). Inversely, if the SRT group would show mean differences that would fall behind the margin, the SRT intervention is considered superior (e.g. lower outcome symptoms).

\section{Results}

\section{Preliminary Analyses}

Analyses were performed to investigate the possible differences in the baseline measures between participants in the CST and SRT interventions. The analysis confirmed there were no statistically significant differences between the two groups for all the measures and subscales, as shown in Table 1. Notably, on average, Cadets commenced second class with mild anxiety and depressive symptoms (CST: $M_{\text {anxiety }}=3.92 ; \quad M_{\text {depression }}=5.33 ; \quad$ SRT: 
$\left.M_{\text {anxiety }}=3.01 ; M_{\text {depression }}=4.50\right)$. In this way, Cadets can be considered mentally healthy on commencement of second class.

\section{[TABLE 1 HERE]}

\section{${ }^{1}$ Analysis of Primary Outcomes}

\section{Anxiety symptoms (GAD-7)}

Consistent with H1, the GEE for anxiety demonstrated a significant time by group interaction indicating that there was overall change in anxiety symptoms over time depending on the intervention group ( Wald $\chi^{2}=10.42, p=.005$ ). Planned comparisons demonstrated that the SRT group had significantly lower mean anxiety symptoms, compared to the CST group at longer-term follow-up ( $p<.001 ; 95 \%$ CI $[1.64,4.20] ; d=0.69 ; 95 \%$ CI $[0.37,1.00])$, but not at initial follow-up $(p=.12)$. The mean symptom scores for each group and percentage change are presented in Table 2. The percentage change scores and means demonstrated that the SRT was more consistent with a resilient trajectory. Specifically, during a highly intense stressor period anxiety symptoms increased for both the SRT and the CST group. The CST group reported a $63 \%$ increase in symptoms between baseline and initial follow-up and the SRT group demonstrated a $78 \%$ increase in symptoms. However, at the longer-term follow-up (3 months later), the anxiety symptoms in the SRT group significantly declined by $30 \%(d=0.48 ; 95 \%$ CI $[0.17,0.8])$, whereas the anxiety symptoms in the CST group experienced a non-significant increase of a further 5\%. Moreover, the SRT group returned to the similar anxiety symptom levels as baseline by the longer-term follow-up ( $d=-0.26$; 95\% CI $[-0.57,0.05])$, whereas the CST group continued to demonstrate anxiety symptoms significantly higher than baseline at longer-term follow-up ( $d=-0.58 ; 95 \%$ CI $[-0.87,-0.29])$. Figure 2 illustrates the pattern of findings for anxiety.

\section{[FIGURE 2 HERE]}

\section{Depression symptoms (PHQ-8)}

\footnotetext{
${ }^{1}$ All analyses were initially performed including covariates: age, gender, years of service. However, these covariates were not statistically meaningful and removed from final models.
} 
There was a significant time by group interaction in the prediction of depression $(\mathrm{H} 2)$ (Wald $\left.\chi^{2}=10.29, p=.006\right)$. Planned comparisons demonstrated that at longer-term follow-up the SRT group had significantly lowered mean depression symptoms compared to the CST group $(p<.01 ; 95 \%$ CI $[-3.63,-1.07] ; d=0.55 ; 95 \%$ CI $[0.24,0.86])$. However, there was no difference in depression symptoms at initial follow-up $(p=.98)$. The percentage change scores and means demonstrate that the SRT was more consistent with a resilience trajectory for depression symptoms (see Table 1). Specifically, during a difficult training period depression symptoms increased for both the SRT group (69\%) and the CST group (63\%) compared to baseline. However, at the longer-term follow-up (3 months later), the depression symptoms in the SRT group declined non-significantly by $2 \%$, whereas the depression symptoms in the CST group experienced a significant increase in symptoms by a further $32 \%(d=-0.46 ; 95 \%$ CI [-0.76, 0.15]). Thus, symptoms in the SRT appeared to stabilise, whereas those in the CST continued to experience a significant increase in symptoms. Figure 3 illustrates the pattern of findings for depression.

\section{[FIGURE 3 HERE]}

\section{Perceived stressor frequency}

Inconsistent with $\mathrm{H} 3$, there was no global two-way interaction between time and intervention group for perceived stressor frequency $(p=.30)$. Generally, the trend of perceived stressor frequency for both groups reflected the rise and fall of training stressors over time ( Wald $\chi^{2}=246.88, p<.001$ ). There was also a significant main-effect for intervention group ( Wald $\chi^{2}=13.54, p<.001$ ), reflecting the average tendency for the SRT group to perceive a lower frequency of stressors than the CST. Despite the standardised nature of the training stressors across all platoons, Cadets in the SRT group perceived less frequent stressors at initial followup $(p<.001 ; d=0.72 ; 95 \%$ CI $[0.4,1.03])$ and longer-term follow-up, compared to the CST group ( $p=.004 ; d=0.46 ; 95 \%$ CI $[0.15,0.77])$. The mean symptom scores for each group and percentage change are presented in Table 1. 


\section{Clinically significant change}

The frequency of individuals who demonstrated clinically significant change were compared between groups. Reliable clinical change (RCI; Jacobson \& Truax, 1991) was used to identify participants who demonstrated significant individual improvement or deterioration on scores of anxiety and depression change, between each time point. A change of five points on each GAD-7 and PHQ-8 scales was determined as a classifier of significant change from baseline. The results of these analyses are presented in Table 3. Between groups statistical testing of improvement and deterioration frequencies were compared with a series of logistic regressions. There was a clinically meaningful improvement in depression symptoms between initial and longer-term follow-up in a significantly higher proportion of Cadets in the SRT group (19\%; 95\% CI [13\%, 26\%]), compared to the CST group (8\%; 95\% CI [4\%, 15\%]). Results indicate a trend of worsening of depression and anxiety symptoms from baseline to initial follow-up in both groups. However, akin to the analyses of group means, differences in the rates of deterioration between the groups become statistically significant between initial and longer term follow-up; where the SRT group demonstrated substantially lower rates of individuals with deteriorated symptoms than the CST group. In other words, individuals in both groups seems to deteriorate in equal numbers in response to the demands of the environment, however, with the SRT group, a significant and substantial number of those individuals seemed to have bounced back to the initially lower scores at baseline.

\section{Post-hoc statistical power analysis and superiority}

We conducted a post-hoc power analysis because this study (i.e., the design and context) is relatively novel and there were several unknown parameters that meant a power analysis could not be conducted a priori. For this reason, our resolve was to conduct a post-hoc power analysis to demonstrate that there was sufficient power in the sample collected to demonstrate at least minimal effects. The power analysis indicated that at a minimum, the SRT condition needed to show an increase of more than $20 \%$, or a decrease of more than $20 \%$, from 
the scores of the CST standard condition (care as usual) in order to be considered as sufficiently powered. That is, given (1) the known sample size, (2) score variances of each scale at each time point, (3) power set at 0.80, and (4) an alpha significance level of 0.05 , a $20 \%$ difference between SRT and CST scores was needed in order to test for statistical significance without power concerns. Because a group difference of $20 \%$ or more is both sufficiently powered and clinically meaningful, the non-inferiority margins were set at $20 \%$.

The between group mean differences and associated 95\% CIs are shown in Table 2 for each of the primary outcomes, and for both initial follow-up and longer term follow-up. Table 2 also shows the outcome scores that represent the necessary $20 \%$ difference margin from the CST group, at each time point and within each of the primary outcomes.

Table S2 illustrates that at initial follow-up the SRT and CST programs were equivalent on all primary outcome measures. For example, the mean GAD-7 difference between group at initial follow-up, at -1.03 , has a $95 \%$ CI $[-2.31,0.25]$ that includes the margin of superiority 0.62. For this reason, the outcomes of both groups is considered equivalent. However, at longer-term follow-up the SRT program was superior for all primary outcome measures. On average, Cadets demonstrated symptom reductions of greater than $>20 \%$ when compared with Cadets in the CST group. For example, the mean GAD-7 difference between groups, at longer term follow-up was -2.92 , with a $95 \%$ CI $[-4.2,-1.64]$ which exceeded the margin of superiority at -0.70 .

\section{${ }^{2}$ Mediation analyses}

Potentially, the effects of the training on symptoms may have been due to eliciting the re-appraisal of stressors as suggested previously. Visual depictions of the results of the mediation models are presented in supplementary Figures S1 and S2.

The intervention group demonstrated a significant direct effect on perceived stressor frequency at initial follow-up in both models $(b=-7.60 ; S E=2.74 ; p<.01$ and $b=-7.38, S E=2.70$;

\footnotetext{
${ }^{2}$ This analysis was carried out post-hoc based on the suggestion of a thoughtful reviewer.
} 
$p<.01$, respectively) indicating that the SRT group had reduced scores on perceived stressor frequency, compared to the CST group. There was also significant positive main effect for perceived stressor frequency at initial follow-up on longer-term anxiety and depression symptoms $(b=0.060 ; S E=0.02 ; p<.01$ and $b=0.063, S E=0.02 ; p<.01$, respectively) indicating that an increase in perceived stressor frequency at initial follow-up was associated with an increase in depression and anxiety symptoms at longer-term follow-up. Both models also demonstrated significant indirect effects providing evidence to suggest that, in part, the SRT was related to a decline in anxiety and depression via initial follow-up perceived stressor frequency $(\boldsymbol{b}=-0.50,95 \%$ CI $[-1.70,-0.14]$ and $\boldsymbol{b}=-0.50,95 \%$ CI $[-1.18,-0.11]$, respectively). However, these effects were only a partial mediation as there was still a direct effect of the intervention on anxiety and depression $(b=-2.30 ; S E=0.74 ; p<.01$ and $b=-1.51, S E=0.73 ; p<.01$, respectively).

\section{Discussion}

The findings for the longer-term follow-up provide evidence to suggest that the SRT involving self-reflection on coping and emotion regulation was more effective in reducing primary mental health outcomes, after a period of significant training stressors, than the CST approach to resilience in this context. On average, the SRT group demonstrated a trajectory more consistent with rebound resilience (returning to normal functioning post adversity) than the CST group. This finding was particularly evident for anxiety symptoms where the SRT group appeared to have the largest effect. The larger effects exhibited for anxiety may be due to the responsiveness of anxiety symptoms to the removal of stressor stimuli. As an indicator of clinical significance, a smaller proportion of SRT participants experienced a worsening of anxiety and depression symptoms between initial and longer-term follow-up compared with CST participants. We did not observe a time by intervention group interaction for the perceived stressor frequency measure, though there were main effects of the intervention group and time. For perceived stressor frequency, both groups tended to map the rise and fall of stressors across 
time, although at initial and longer-term follow-up the SRT group perceived a significantly lower frequency of stressors. When compared to civilian resilience training trials, the effect sizes observed in this study are relatively strong for the observation of distal effects (>1 month) (Vanhove, et al., 2016), particularly for the military context (Adler et. al., 2015; Cohn \& Pakenham, 2008).

We did not observe any effects of the SRT training at initial follow-up. Assessing distress symptoms in non-depressed participants reduces the likelihood that such symptoms will increase or decrease in a given period. In this sample, in the intervening time between initial and longer-term follow up there was a period of significant stressors related to fieldwork that may have potentiated anxiety and depression symptoms. An alternative reason for this finding relates to the mechanism by which coping and emotion regulatory self-reflection is thought to create its effect. As we initially suggested, self-reflection is unlikely to have a direct relationship to resilient outcomes. It is via other processes (e.g., changing the way in which stressors are appraised, broadening the coping and emotion regulatory repertoire) that the effects on resilience emerge. Moreover, writing about stressful experiences is likely to initially heighten negative affect (Petrie, Booth, Pennebaker, Davison, \& Thomas, 1995) and therefore self-reporting of distress is likely to initially increase.

The significant indirect effects for both anxiety and depression symptoms found via perceived stressor frequency provides clues about the mechanism by which the intervention creates change in symptoms. As proposed earlier, engaging Cadets in self-reflection with a focus on the development of coping and emotion regulatory strategies as they encounter training stressors may support the re-appraisal of stressor events as learning and growth opportunities. Research by Crane and Searle (2016) demonstrated in a two-wave longitudinal study that workplace challenge stressors (typically viewed as development or growth opportunities; Cavanaugh, Boswell, Roehling, \& Boudreau, 2000) predicted an increase in perceived resilience over a three-month period, whereas hindrance stressors (typically viewed as barriers to goal accomplishment; Cavanaugh et. al., 2000) predicted a decline in resilience. 
These findings suggesting that challenge stressors may engender an opportunity for resilient capacities to emerge because of stressor encounters. Applying this reasoning suggests the SRT approach may be facilitating the adaptive re-appraisal of stressor events by encouraging training participants to reflect on their coping and emotion regulatory experiences in a way that aims to convert stressor events into a development opportunity.

The direct effect of intervention group on anxiety and depression symptoms at longerterm follow-up remained suggesting other additional mechanisms at play. Other possible mechanisms, based on the systematic self-reflection model of strengthening resilience (Crane, et al., 2018) include broadening of the coping and emotion regulatory repertoire, increased coping resources, and the adoption of resilient belief systems. Moreover, there may be a motivational element at work. In skill development approaches, the motivation for behavior change may not be addressed as part of training and perhaps the influence process relied upon is derived from expert knowledge (i.e., psychologist, psychiatrist, researcher). In SRT, the motivation for behavior change is proposed to emerge from the recognition of the discrepancy between the outcomes of one's current approaches and values and value-based goals. By aligning the stressor inducing activities with desired values and goals, the SRT approach is seeking to influence the motivational pathway by reframing stressors as opportunities for valued personal growth, thus enhancing self-efficacy and reinforcing a measure of personal achievement (Crane \& Boga, 2017; Ryan \& Deci, 2000). Relating to the above two points, the strategy or goal for behavior change is individually determined or a search for knowledge or skill-development is initiated. To develop a complete understanding of the way in which the SRT program supports resilient outcomes, an investigation of these alternative mechanisms is necessary.

At this point, it is important to note in what context the SRT may be most effective. The intention of the SRT program is preventative, rather than curative. The target population for this particular approach is on individuals who are generally mentally well, but where there is future risk that may result in a down-turn in well-being. This approach may not be 
appropriate or useful for those people experiencing clinical-levels of distress, although this is something that needs investigation.

Both the training of coping skills and coping and emotion regulatory self-reflection are likely important to strengthening resilience. Coping skill development can be advantageous for participants who have encountered difficulty finding ways to enhance their coping in the future. However, one major difference of the SRT approach is that the individual is the expert when it comes to identifying their personal resilient qualities, limitations, and the design of alternative coping strategies. Given that those individuals receiving resilience training are typically well, it is reasonable to assume that up to this point they have been using some adaptive strategies (although perhaps with some limitations). Requesting information from the individual about how they cope, how effective it is, and what they might try next may achieve a few goals. First, it supports the identification of personal resilient qualities that have aided individuals in the past and implicitly suggests that resilience is not black and white (resilient vs. not resilient person) (Fletcher \& Sarkar, 2016). Second, coping strategies are tailored to the person's needs, personality, cultural constraints, and level of capability allowing a more personalised set of strategies to be derived. Third, it encourages critical self-examination, which can be applied to encourage adaptation across a variety of contexts and stressor encounters.

The process of coping self-reflection may be able to bolster the effects of coping skilltraining development and producing greater consistency in positive outcomes, but may also be used as a stand-alone tool. Additional benefits of the SRT are that it is largely self-driven and therefore large group administration still appears to yield significant benefit for participants, and the SRT program requires much less contact time than traditional skill development protocols. Moreover, the administration of the SRT program may not require a psychologist because it does not involve skills training, but rather a person-driven reflective coaching approach (Grant, Curtayne, \& Burton, 2009). This would be an advantage for organizations, such as the military, where the workforce requiring training outnumbers the available psychologists. However, this potential would need to be explored in future research. 


\section{Strengths, Limitations and Future Directions}

This study has a number of strengths and limitations that need to be considered when interpreting its findings. A key strength of this study was the selection of survey time points that provided optimal injection points for an assessment of resilient trajectories. In this study we were able to demonstrate that, compared to the CST intervention, the SRT intervention was able to either prevent the worsening of depression symptoms and what appears to be a 'bouncing-back' from anxiety symptoms after a period of significant stress. Most previous resilience training studies merely examine change from baseline to follow-up where there is no objective standardized stressor in the intervening period (cf. Arnetz et al., 2009). A second key strength of this study is that few resilience-training trials (seven of 43 studies) have compared resilience interventions with treatment as usual (Chmitorz et al., 2018). A third key strength of the study is the demonstrated partial mediating role of perceived stressor frequency, suggesting one potential mechanism by which the training has its effects on mental health outcomes.

Although the SRT intervention does initially show promise as a resilience training approach, several limitations should be noted and addressed in future trials. The principle limitation of this study was the difference in dose between the intervention groups. The SRT had 75 minutes of additional 'dose'. During this time, Cadets spent 15-minutes each week over five weeks writing their guided self-reflection. For organizational reasons, it was important to demonstrate the effectiveness of the SRT, compared to what Cadets typically receive. Arguably, the benefits observed in the SRT group may have resulted from this additional contact time and less so from the active ingredients of the guided reflection activity. Nevertheless, there are two counter considerations here. First, in the additional 75 minutes the Cadets received no additional training or information from the administrator. The Cadets in the CST group had free time and could have spent their time doing other activities suggested in the CST (e.g., seeking peer support, exercising, and relaxation). Informally, Cadets in the SRT group commented to the researcher that it was unfair that the other group had free time. 
Second, work in similar contexts suggests that more contact with a psychologist in the control group does not result in significant reductions in psychological distress. For example, Cohn and Pakenham (2008) used a control group involving group discussion about their training experiences with a psychologist for 80-minutes. This research found no change in psychological distress symptoms (GHQ-12) over the course of 43 days in the control group illustrating that placebos with a longer time course are unlikely to cause considerable shifts in mental health outcomes. Further, the attained mental health outcomes (anxiety, depression symptoms) of a 120 minute CBT program in a military training context have been previously found to be either non-significantly different from a control group (Adler et al., 2015) or result in a small between-group effect size (Cohn \& Pakenham, 2008; GHQ-12; Cohen's $d=0.24$; CI $95 \%$ [-0.07 to 0.55$])$. Together, the fact that dosed-matched control groups did not yield change over time from baseline and the non-significant to small between-group effects suggest that extending the delivery time of the treatment as usual approach would have been unlikely to result in moderate to large clinical effects in the current study. It is also important to consider that the between-group effects observed in this study are larger (PHQ-8; $0.69[0.37,1.00]$ and GAD-7; $0.55[0.24,0.86])$ than those observed in CST interventions that were longer in time course (i.e., 80 or 120 -minutes). This finding suggests that the type of treatment, rather than the dose, seems to be the most influential. Although the lack of a dose-matched control does raise some uncertainty about the specific benefit of SRT, the results of this study show promise to exceed previously observed effects in military samples. Future work should aim to balance the dose by providing an additional 75 minutes of training (e.g., communication skills training) to address concerns about dose more directly.

A further limitation is that within the ADF considerable emphasis is placed on resilience and this focus is likely to mean that Cadets within the SRT group are likely to have received the CST program in the past as part of prior training or military service. As such, the SRT program may be an important extension of CST interventions currently used, but perhaps may not have achieved the magnitude of benefit independent from CST interventions. 
Nevertheless, the same can be said for any population where individuals may have various experience of contact with psychologists, or resilience training, via their work. Even if we accept the effects of the above stated limitations arguably the control group could be considered a passive control.

The SRT group received the survey just post their final reflection writing task, whereas the CST group received the survey outside of the training context. This timing created a difference in the context of outcome assessment for the initial follow-up survey and may account for why no difference was observed between the groups at initial follow-up. Future work should standardize the context in which assessments take place. Although difficult to avoid, allegiance affects are also worth considering given that the lead author was involved in training the psychologist delivering the SRT program. In this way, delivery may have implicitly conveyed an expectation that one program was more beneficial. Relatedly, intervention fidelity was not measured. This may not have been a major concern given that there was only a single cohort for the CST and SRT group, but it is still important to measure the extent to which facilitators followed the protocol for their intervention/control group and did not contaminate either program with unintended elements. Another consideration is that the groups were aware of one another. Although precautions were taken to ensure that no participants perceived themselves to be in an inferior intervention group, groups may make comparisons between training received. Having noted this, arguably the CST group may have considered themselves to be the active intervention group because most Cadets are likely to be familiar with this program.

There were also limitations regarding what was not measured. In order to keep the survey protocol brief we also excluded a direct self-report measure of resilience because in military populations measures like the Connor and Davidson Resilience Scale and the Brief Resilience Scale yield little variance (highly negatively skewed) and are largely insensitive to change over time despite change in symptom scales over the same time period. No military resilience training trials use self-report measures of psychological resilience, rather opting for 
the use of symptoms scales (e.g., Adler et al., 2015; Cohn \& Pakenham, 2008). However, to address this issue we used well-known symptom scales that are sensitive to change over time in the context of a standardized stressor experience in order to demonstrate the rise in symptoms during exposure and then the reduction in symptoms during a brief period of respite. Moreover, we did not include measures of non-military stressors. RMC is an immersive environment, with Cadets predominately living and working on base, often working after hours, and socializing predominantly within their cohort. Thus the majority of stressors are military-related. However, external stressors may arise (e.g., financial pressures) and therefore future studies could attempt to take account of them. Prior trauma was also not measured in this study and therefore it is not clear how this approach would generalize to a population with significant prior trauma. In fact, given that Cadets are psychologically assessed for good mental health prior to appointment into the ADF, prior trauma may be lower than the general population. Again, this is an area of future investigation and we would recommend that these elements be examined before broader dissemination of the SRT program.

The focus of our training was on resilience, but there may be a role for coping and emotion regulatory self-reflection in benefit finding and post-traumatic growth (Eve \& Kangas, 2015). This may be something that could be explored in a deploying population or in the general population over a longer period of time (e.g., 5 years). Further outcome variables that could be considered are symptom items that are tailored to the unique nature of the setting (e.g., concerns about career or evaluation) and the effects of the resilience training on performance outcomes.

We observed differential dropout rates across conditions with greater dropout occurring for the SRT group. At present, we are unsure how to interpret the differential dropout given that leaving Cadet training may be for several reasons, some of which are positive (e.g., deciding against a military career, poor person-organizational fit) and some which are negative (e.g., psychological or physical injury). It is possible that allowing Cadet's to reflect may have the unintended outcome of helping them decide that a military career is not for them. We see 
this as a potentially positive outcome promoting the sustainability of the workforce. In future work, we recommend the collection of information about exit so that these dropout affects can be better understood.

This trial sample may constrain generalizability to some extent. Officer Cadets are a screened population and are generally younger males. Younger training recipients may be more open to self-reflection because they are still in the formative stages of development (Eve \& Kangas, 2015). However, SRT targets a meta-cognitive process for engaging with incoming stressor events that could potentially be applied widely. As with other skills, having the opportunity to practice is critical. Exposure to stressors in other contexts should theoretically yield similar effects. However, the intensity of stress exposure is an important consideration. SRT is a developmental process that should be incrementally trained during encounters with sub-distress levels of stress, not immediately following traumatic events. Reflective practices should be engendered well before exposure to potentially traumatic events or other risks as a means of processing incoming events. We anticipate that the SRT program could potentially facilitate resilience-strengthening in the broader population and is perhaps an alternative to skill-development programs or could be used in combination with these programs. Of course, individual difference variables likely play a role (e.g., prior trauma history) and we seek to rectify this limitation with future work targeting different populations.

\section{Conclusion}

Our coping self-reflection training strengthened the resilience of Cadets over and above treatment as usual. The SRT program requires a relatively short amount of delivery time, minimal resource, and can be delivered in large-groups. Therefore, it is likely to be sustainable for organizations, such as the military, with a large number of personnel and few psychologists. However, this trial is the first of its kind, so we recommend further implementation and evaluation of the program in other populations before broader dissemination of the SRT program. 


\section{References}

Adler, A. B., Bliese, P. D., McGurk, D., Hoge, C. W., \& Castro, C. A. (2009). Battlemind debriefing and battlemind training as early interventions with soldiers returning from Iraq: Randomization by platoon. Journal of Consulting and Clinical Psychology, 77, 928-40. doi:org/10.1037/a0016877

Adler, A. B., Williams, J., McGurk, D., Moss, A., \& Bliese, P. D. (2015). Resilience training with soldiers during basic combat training: Randomizeation by platoon. Applied Psychology: Health and Well-Being, 7, 85-107. doi: 10.1111/aphw.12040.

Angel, C. M. (2016). Resilience, post-traumatic stress, and posttraumatic growth: veterans' and active duty military members' coping trajectories following traumatic event exposure. Nurse Education Today, 47, 57-60. doi: 10.1016/j.nedt.2016.04.001.

Arnetz, B. B., Nevedal, D. C., Lumley, M. A., Backman, L., \& Lublin, A. (2009). Trauma resilience training for police: Psychophysiological and performance effects. Journal of Police and Criminal Psychology, 24, 1-9. doi:10.1007/s11896-008-9030-y

Baikie, K. A., Geerligs, L., \& Wilhelm, K. (2012). Expressive writing and positive writing for participants with mood disorders: An online randomized controlled trial. Journal of Affective Disorders, 136, 310-319. doi: 10.1016/j.jad.2011.11.032

Bannick, F.P. (2010) 1001 solution-focused questions: Handbook for solution-focused interviewing. Amsterdam, WW. Norton \& Co.

Bonanno, G. A., \& Burton, C. L. (2013). Regulatory flexibility: An individual differences perspective on coping and emotion regulation. Perspectives on Psychological Science, 8, 591-612. doi: 10.1177/1745691613504116.

Bonanno, G., Pat-Horenczyk, R., \& Noll, J. (2011). Coping flexibility and trauma: The perceived ability to cope with trauma (PACT) scale. Psychological Trauma: Theory, Research, Practice, and Policy, 3, 117-129. doi: 10.1037/a0020921 
Borek, A. J., Abraham, C., Smith, J. R., Greaves, C. J., \& Tarrant, M. (2015). A checklist to improve reporting of group-based behavior-change interventions. BMC Public Health, 15, 963-974. doi:10.1186/s12889-015-2300-6

Boud, D., Keogh, R., \& Walker, D. (1985). Reflection: Turning experience into learning. London: Kogan Page.

Britt, T. W., Crane, M., Hodson, S. E., \& Adler, A. B. (2016). Effective and ineffective coping strategies in a low-autonomy work environment. Journal of Occupational Health Psychology, 21, 154-168. doi: 10.1037/a0039898

Burton, N. W., Pakenham, K. I., \& Brown, W. J. (2010). Feasibility and effectiveness of psychosocial resilience training: A pilot study of the READY program. Psychology, Health \& Medicine, 15, 266-277. doi:10.1080/13548501003758710

Cacioppo, J. T., Adler, A. B., Lester, P. B., McGurk, D., Thomas, J. L., Chen, H.-Y., \& Cacioppo, S. (2015). Building social resilience in soldiers: A double dissociative randomized controlled study. Journal of Personality and Social Psychology, 109, 90-105. doi: org/10.1037/pspi0000022

Cavanaugh, M. A., Boswell, W. R., Roehling, M. V., \& Boudreau, J. W. (2000). An empirical examination of self-reported work stress among U.S. managers. Journal of Applied Psychology, 85, 65-74. doi. 10.1037/0021-9010.85.1.65

Cohn, A., Crane, M. F., \& Hodson, S. E (2011). Psychological resilience training in the Australian Defence Force, in Kathryn M. Gow and Marek J. Celinski, (Ed.) Wayfinding through life's challenges: Coping and survival. NY: Nova Science Publishers

Cohn, A., \& Pakenham, K. (2008). Efficacy of a cognitive-behavioral program to improve psychological adjustment. Military Medicine, 173, 1151-1156. doi: doi.org/10.7205/MILMED.173.12.1151

Cornum, R., Matthews, M. D., \& Seligman, M. E. P. (2011). Comprehensive soldier fitness: Building resilience in a challenging institutional context. The American Psychologist, 66, 4-9. doi: 10.1037/a0021420. 
Crane, M., \& Boga, D. (2017). A commentary: Rethinking approaches to resilience and mental health training. Journal of Military and Veterans Health, 25, 30-33. ISSN: 1835-1271.

Crane, M. F., Searle, B. J., Kangas, M., \& Nwiran, Y. (2018). How resilience is strengthened by exposure to stressors: the systematic self-reflection model of resilience strengthening. Anxiety, Stress, \& Coping. Advanced online publication doi: $10.1080 / 10615806.2018 .1506640$

Cranton, P. (1994) Understanding and promoting transformational learning: A guide for educators of adults. Jossey-Bass Publishers: San Francisco

Donohue, M. C., Gamst, A. C., Edland, S. D., \& Donohue, M. M. C. (2013). Package 'longpower'. Biometrics, 53, 937-47.

Ellis, S., \& Davidi, I. (2005). After-event reviews: drawing lessons from successful and failed experience. The Journal of Applied Psychology, 90, 857-871. doi: 10.1037/00219010.90 .5 .857

Eve, P., \& Kangas, M. (2015). Posttraumatic growth following trauma: Is growth accelerated or a reflection of cognitive maturation? The Humanistic Psychologist, 32, 354-370. doi: $10.1080 / 08873267.2015 .1025272$

Fletcher, D., \& Sarkar, M. (2016). Mental fortitude training: An evidence-based approach to developing psychological resilience for sustained success. Journal of Sport Psychology in Action, 7, 135-157. doi: 10.1080/21520704.2016.1255496.

Gortner, E. M., Rude, S. S., \& Pennebaker, J. W. (2006). Benefits of expressive writing in lowering rumination and depressive symptoms. Behavior Therapy, 37, 292-303. doi: 10.1016/j.beth.2006.01.004

Grant, A.M., Curtayne, L., \& Burton, G. (2009). Executive coaching enhances goal attainment, resilience and workplace well-being: A randomised controlled study, The Journal of Positive Psychology, 4, 396-407. doi: 10.1080/17439760902992456 
Grant, A. M., Franklin, J., \& Langford, P. (2002). The self-reflection and insight scale: A new measure of private self-consciousness. Social Behavior and Personality: An International Journal, 30, 821-835. doi: 10.2224/sbp.2002.30.8.821.

Greene, C. J., Morland, L. A., Durkalski, V. L., \& Frueh, B. C. (2008). Noninferiority and equivalence designs: issues and implications for mental health research. Journal of Traumatic Stress, 21, 433-439. doi: 10.1002/jts.20367

Harkin, B., Webb, T. L., Chang, B. P. I., Prestwich, A., Conner, M., Kellar, I., . . Sheeran, P. (2016). Does monitoring goal progress promote goal attainment? A meta-analysis of the experimental evidence. Psychological Bulletin, 142, 198-229. doi:10.1037/bul0000025

Harms, P. D., Herian, M., Krasikova, D. V., Vanhove, A. J., \& Lester, P. B. (2013). The Comprehensive Soldier and Family Fitness Program Evaluation. Report\# 4: Evaluation of resilience training and mental and behavioral health outcomes. Retrieved from: https://digitalcommons.unl.edu/cgi/viewcontent.cgi?referer=https://scholar.google.com.a $\mathrm{u} / \&$ httpsredir=1\&article $=1009 \&$ context $=$ pdharms

Harrell Jr, F. E. (2015). Regression modeling strategies: with applications to linear models, logistic and ordinal regression, and survival analysis. New York: Springer.

Hayes, A.F., (2013) Introduction to mediation, moderation, and conditional process analysis. New York, NY; Guilford Press.

Hubbard, A. E., Ahern, J., Fleischer, N. L., Van der Laan, M., Lippman, S. A., Jewell, N., ... \& Satariano, W. A. (2010). To GEE or not to GEE: comparing population average and mixed models for estimating the associations between neighborhood risk factors and health. Epidemiology, 21, 467-474. doi: 10.1097/EDE.0b013e3181caeb90

Leppin, A. L., Bora, P. R., Tilburt, J. C., Gionfriddo, M. R., Zeballos-Palacios, C., Dulohery, M. M., ... \& Montori, V. M. (2014). The efficacy of resiliency training programs: a systematic review and meta-analysis of randomized trials. PLoS One, 9, e111420. https://doi.org/10.1371/journal.pone.0111420 
Lew, M. D. N., \& Schmidt, H. G. (2011). Self-reflection and academic performance: Is there a relationship? Advances in Health Sciences Education, 16, 529-545. doi: 10.1007/s10459011-9298-z

Liossis, P. L., Shochet, I. M., Millear, P. M., \& Biggs, H. (2009). The Promoting Adult Resilience (PAR) program: The effectiveness of the second, shorter pilot of a workplace prevention program. Behaviour Change, 26, 97-112. doi:10.1375/bech.26.2.97

Little, R. J., \& Rubin, D. B. (2014). Statistical analysis with missing data. Hoboken, NJ: John Wiley \& Sons.

Lindberg, E., Wincent, J., \& Örtqvist, D. (2013). Turning stressors into something productive: An empirical study revealing nonlinear influences of role stressors on self-efficacy. Journal of Applied Social Psychology, 43, 263-274. doi: 10.1111/j.15591816.2012.00995.x

Löwe, B., Decker, O., Müller, S., Brähler, E., Schellberg, D., Herzog, W., \& Herzberg, P. Y. (2008). Validation and standardization of the Generalized Anxiety Disorder Screener (GAD-7) in the general population. Medical Care, 46, 266-274. doi: 10.1097/MLR.0b013e318160d093

Jacobson, N. S., \& Truax, P. (1991). Clinical significance: a statistical approach to defining meaningful change in psychotherapy research. Journal of Consulting and Clinical Psychology, 59, 12-19. doi: 10.1037/0022-006X.59.1.12.

Jamieson, J. P., Crum, A. J., Goyer, J. P., Marotta, M. E., \& Akinola, M. (2018). Optimizing stress responses with reappraisal and mindset interventions: an integrated model. Anxiety, Stress, \& Coping, 31, 245-261. doi: 10.1080/10615806.2018.1442615

Jennings, P. A., Frank, J. L., Snowberg, K. E., Coccia, M. A., \& Greenberg, M. T. (2013). Improving classroom learning environments by cultivating awareness and resilience in education (CARE): Results of a randomized controlled trial. School Psychology Quarterly, 28, 374-390. doi:10.1037/spq0000035 
Johnsen, B. H., Laberg, J. C., \& Eid, J. (1998). Coping strategies and mental health problems in a military unit. Military Medicine, 163, 599-602.

Joyce, S., Shand, F., Tighe, J., Laurent, S. J., Bryant, R. A., \& Harvey, S. B. (2018). Road to resilience: A systematic review and meta-analysis of resilience training programmes and interventions. BMJ Open, 8, e017858. doi: 10.1136/bmjopen-2017-017858

Kalisch, R., Baker, D. G., Basten, U., Boks, M. P., Bonanno, G. A., Brummelman, E., ..\& Geuze, E. (2017). The resilience framework as a strategy to combat stress-related disorders. Nature: Human Behaviour, 1, 784-790. doi: 10.1038/s41562-017-0200-8

Karin, E., Dear, B. F., Heller, G. Z., Crane, M. F., \& Titov, N. (2018). "Wish You Were Here”: Examining Characteristics, Outcomes, and Statistical Solutions for Missing Cases in Web-Based Psychotherapeutic Trials. JMIR Mental Health, 5, e22. doi: $10.2196 /$ mental.8363

Kroenke, K., Strine, T. W., Spitzer, R. L., Williams, J. B., Berry, J. T., \& Mokdad, A. H. (2009). The PHQ-8 as a measure of current depression in the general population. Journal of affective disorders, 114, 163-173. doi: 10.1016/j.jad.2008.06.026

McCraty, R., \& Atkinson, M. (2012). Resilience training programme reduces physiological and psychological stress in police officers. Global Advances in Health and Medicine, 1, 44-66. doi: 10.7453/gahmj.2012.1.5.013

Mezirow, J., (1998). On critical reflection. Adult Education Quarterly, 48, 185-198.

Mezirow, J. (2003). Transformative learning as discourse. Journal of Transformative Education, 1, 58-63. doi: 10.1177/1541344603252172

Millear, P., Liossis, P., Shochet, I. M., Biggs, H., \& Donald, M. (2008). Being on PAR: Outcomes of a pilot trial to improve mental health and wellbeing in the workplace with the promoting adult resilience (PAR) programme. Behavior Change, 25, 215-228. doi:10.1375/bech.25.4.215 
Moore, L. J., Young, T., Freeman, P., \& Sarkar, M. (2018). Adverse life events, cardiovascular responses, and sports performance under pressure. Scandinavian Journal of Medicine \& Science in Sports, 28, 340-347. doi: 10.1111/sms.12928

Park, N., Peterson, C., \& Seligman, M. E. (2004). Strengths of character and well-being. Journal of Social and Clinical Psychology, 23, 603-619. doi: $10.1521 /$ jscp.23.5.603.50748

Petrie, K. J., Booth, R. J., Pennebaker, J. W., Davison, K. P., \& Thomas, M. G. (1995). Disclosure of trauma and immune response to a hepatitis B vaccination program. Journal of Consulting and Clinical Psychology, 63, 787-792. doi: 10.1037/0022-006X.63.5.787

Pidgeon, A. M., Ford, L., \& Klassen, F. (2014). Evaluating the effectiveness of enhancing resilience in human service professionals using a retreat-based mindfulness with metta training programme: A randomized controlled trial. Psychology, Health, \& Medicine, 19, 355-364. doi:10.1080/ 13548506.2013.806815.

Richardson, G. E. (2002). The metatheory of resilience and resiliency. Journal of Clinical Psychology, 58, 307-321. doi: 10.1002/jclp.10020.

Robertson, I. T., Cooper, C. L., Sarkar, M., \& Curran, T. (2015). Resilience training in the workplace from 2003 to 2014: A systematic review. Journal of Occupational and Organizational Psychology, 88, 533-562. doi: 10.1111/joop.12120

Ryan, D.M, \& Deci, E.L. (2000). Self-determination theory and the facilitation of intrinsic motivation, social development, and wellbeing. American Psychologist, 55, 68-78. doi: 10.1037/0003-066X.55.1.68

Ryan M. A., Smith T.C., Smith B., A. P., Boyko E. J., Gray G.C., Gackstetter G.D., ... Hooper. (2007). Millennium Cohort: Enrollment begins a 21-year contribution to understanding the impact of military service. Journal of Clinical Epidemiology, 60, 181-191. doi: 10.1016/j.jclinepi.2006.05.009 
Sarkar, M., \& Fletcher, D. (2014). Ordinary magic, extraordinary performance: Psychological resilience and thriving in high achievers. Sport, Exercise, and Performance Psychology, 3, 46-60. doi: 10.1037/spy0000003

Sarkar, M., \& Fletcher, D. (2017). Adversity-related experiences are essential for Olympic success: Additional evidence and considerations. Progress in Brain Research, 232, 159165. doi: 10.1016/bs.pbr.2016.11.009.

Scheier, M. F., Carver, C. S., \& Bridges, M. W. (1994). Distinguishing optimism from neuroticism (and trait anxiety, self-mastery, and self-esteem): A re-evaluation of the Life Orientation Test. Journal of Personality and Social Psychology, 67, 1063-1078. doi: 10.1037/0022-3514.67.6.1063

Seery, M. D., Holman, E. A., \& Silver, R. C. (2010). Whatever does not kill us: Cumulative lifetime adversity, vulnerability, and resilience. Journal of Personality and Social Psychology, 99, 1025-1041. doi: 10.1037/a0021344

Snyder, C. R. (1995) Conceptualizing, measuring, and nurturing hope. Journal of Counseling and Development 73 (January/February) 355-360.

Tedeschi, R. G. (2011). Posttraumatic growth in combat veterans. Journal of Clinical Psychology in Medical Settings, 18, 137-144. doi: 10.1007/s10880-011-9255-2.

Tedeschi, R.G., \& Calhoun, L.G. (1996). The posttraumatic growth inventory: Measuring the positive legacy of trauma. Journal of Traumatic Stress. 9, 455-471. doi: $10.1007 / \mathrm{BF} 02103658$

Vanhove, A. J., Herian, M. N., Perez, A. L., Harms, P. D., \& Lester, P. B. (2016). Can resilience be developed at work? A meta-analytic review of resilience-building programme effectiveness. Journal of Occupational and Organizational Psychology, 89, 278-307. doi: 10.1111/joop.12123.

Waite, P. J., \& Richardson, G. E. (2003). Determining the efficacy of resiliency training in the work site. Journal of Allied Health, 33, 178-183. 
Wells, T. S., Horton, J. L., LeardMann, C. A., Jacobson, I. G., \& Boyko, E. J. (2013). A comparison of the PRIME-MD PHQ-9 and PHQ-8 in a large military prospective study, the Millennium Cohort Study. Journal of Affective Disorders, 148, 77-83. doi: 10.1016/j.jad.2012.11.

Yeager, D. S., \& Dweck, C. S. (2012). Mindsets that promote resilience: When students believe that personal characteristics can be developed. Educational Psychologist, 47, 302-314. doi: 10.1080/00461520.2012.722805 


\section{RUNNING HEADER: STRENGTHENING RESILIENCE IN OFFICER CADETS}

Table 1: Sample demographics by training condition

\begin{tabular}{lcccccc}
\hline & \multicolumn{2}{c}{ SRT } & CST & & \\
\cline { 2 - 7 } Variable name & $n$ & \% or Mean & $n$ & \% or Mean & $t$ or $X 2$ & $p$-values \\
\hline Gender & & & & & & \\
$\quad$ Male & 103 & 84.43 & 76 & 81.72 & 0.28 & .60 \\
$\quad$ Female & 19 & 15.57 & 17 & 18.28 & & \\
Age ( in years) & 121 & $M=23$ & 92 & $M=22$ & 1.03 & .31 \\
Education level & & & & & & \\
$\quad$ Completed year 12 (high school) & 15 & 12.40 & 12 & 13.04 & 6.06 & .30 \\
$\quad$ Some trade qualification completed & 3 & 2.48 & 1 & 1.09 & & \\
$\quad$ Some university completed & 10 & 8.26 & 6 & 6.52 & & \\
$\quad$ Currently enrolled in university & 10 & 8.26 & 5 & 5.43 & & \\
$\quad$ Completed university degree & 75 & 61.98 & 67 & 72.83 & & \\
$\quad$ Completed trade qualification & 8 & 6.61 & 1 & 1.09 & & \\
Years of service & 119 & $M=2.37$ & 87 & $M=2.34$ & 0.91 & .91 \\
Depression (PHQ-8) & 121 & $M=4.50$ & 93 & $M=5.33$ & 1.51 & .13 \\
Anxiety (GAD-7) & 121 & $M=3.01$ & 93 & $M=3.92$ & 1.84 & .07 \\
Perceived stressor frequency & 122 & $M=40.11$ & 93 & $M=45.55$ & 1.74 & .09 \\
\hline
\end{tabular}


Table 2: Means, standard deviations and average percentage change from baseline for anxiety, depression and perceived stressor frequency.

\begin{tabular}{|c|c|c|c|c|c|c|c|c|c|c|c|}
\hline \multirow[b]{2}{*}{$\begin{array}{l}\text { PRIMARY } \\
\text { OUTCOMES a }\end{array}$} & \multicolumn{3}{|c|}{ Means (SD) for each Time point } & \multicolumn{3}{|c|}{ Percentage change $[95 \% \mathrm{CI}]$} & \multicolumn{3}{|c|}{ Within group effect sizes $[95 \% \mathrm{CI}]$} & \multicolumn{2}{|c|}{$\begin{array}{c}\text { Between group effect sizes } \\
{[95 \% \mathrm{CI}]}\end{array}$} \\
\hline & Baseline & $\begin{array}{c}\text { Initial } \\
\text { follow-up }\end{array}$ & $\begin{array}{l}\text { Longer- } \\
\text { term } \\
\text { follow-up }\end{array}$ & $\begin{array}{l}\text { Baseline to initial } \\
\text { follow-up }\end{array}$ & $\begin{array}{l}\text { Baseline to } \\
\text { longer- term } \\
\text { follow-up }\end{array}$ & $\begin{array}{c}\text { Initial to } \\
\text { longer- term } \\
\text { follow-up }\end{array}$ & $\begin{array}{c}\text { Baseline to } \\
\text { initial follow- } \\
\text { up }\end{array}$ & $\begin{array}{l}\text { Baseline to } \\
\text { longer- term } \\
\text { follow-up }\end{array}$ & $\begin{array}{c}\text { Initial to } \\
\text { longer- term } \\
\text { follow-up }\end{array}$ & $\begin{array}{c}\text { Initial } \\
\text { follow-up }\end{array}$ & $\begin{array}{c}\text { Longer- } \\
\text { term } \\
\text { follow-up }\end{array}$ \\
\hline \multirow[t]{2}{*}{ CST } & $3.93(4.2)$ & $6.41(4.9)$ & $6.71(5.3)$ & $63 \%$ & $71 \%$ & $5 \%$ & -0.54 & -0.58 & -0.06 & 0.24 & 0.69 \\
\hline & & & & {$[38 \%, 93 \%]$} & {$[45 \%, 101 \%]$} & {$[-11 \%, 23 \%]$} & {$[-0.84,-0.25]$} & {$[-0.87,-0.29]$} & {$[-0.36,0.25]$} & {$[-0.07,0.55]$} & {$[0.37,1.00]$} \\
\hline \multirow[t]{2}{*}{ SRT } & $3.02(2.9)$ & $5.38(3.4)$ & $3.79(3.1)$ & $78 \%$ & $26 \%$ & $-30 \%$ & -0.75 & -0.26 & 0.48 & & \\
\hline & & & & {$[56 \%, 104 \%]$} & {$[5 \%, 50 \%]$} & {$[-41 \%,-16 \%]$} & {$[-1.06,-0.43]$} & {$[-0.57,0.05]$} & {$[0.17,0.8]$} & & \\
\hline \multicolumn{12}{|l|}{ PHQ-8 } \\
\hline \multirow[t]{2}{*}{ CST } & $5.33(4.6)$ & $7.14(4.6)$ & $9.40(5.1)$ & $34 \%$ & $76 \%$ & $32 \%$ & -0.39 & -0.83 & -0.46 & 0.00 & 0.55 \\
\hline & & & & {$[17 \%, 54 \%]$} & {$[57 \%, 97 \%]$} & {$[18 \%, 47 \%]$} & {$[-0.68,-0.1]$} & {$[-1.12,-0.54]$} & {$[-0.76,-0.15]$} & {$[-0.31,0.31]$} & {$[0.24,0.86]$} \\
\hline \multirow[t]{2}{*}{ SRT } & $4.50(3.3)$ & $7.15(3.5)$ & $7.04(3.4)$ & $59 \%$ & $57 \%$ & $-2 \%$ & -0.77 & -0.75 & 0.03 & & \\
\hline & & & & {$[43 \%, 77 \%]$} & {$[41 \%, 74 \%]$} & {$[-11 \%, 9 \%]$} & {$[-1.08,-0.45]$} & {$[-1.07,-0.43]$} & {$[-0.28,0.34]$} & & \\
\hline \multicolumn{12}{|c|}{ Perceived stressor } \\
\hline \multirow[t]{2}{*}{ CST } & $45.55(24.8)$ & $72.24(16.5)$ & $52.88(22.3)$ & $59 \%$ & $16 \%$ & $-27 \%$ & -1.21 & -0.3 & 0.97 & 0.72 & 0.46 \\
\hline & & & & {$[51 \%, 66 \%]$} & {$[6 \%, 26 \%]$} & {$[-33 \%,-20 \%]$} & {$[-1.52,-0.9]$} & {$[-0.59,-0.02]$} & {$[0.64,1.29]$} & {$[0.4,1.03]$} & {$[0.15,0.77]$} \\
\hline \multirow[t]{2}{*}{ SRT } & $40.11(19.6)$ & $61.18(13.6)$ & $44.00(15.9)$ & $53 \%$ & $10 \%$ & $-28 \%$ & -1.23 & -0.21 & 1.14 & & \\
\hline & & & & {$[45 \%, 60 \%]$} & {$[1 \%, 18 \%]$} & {$[-34 \%,-22 \%]$} & {$[-1.56,-0.89]$} & {$[-0.52,0.1]$} & {$[0.81,1.48]$} & & \\
\hline
\end{tabular}

Note. Standard deviations are shown in round parentheses for the means and 95\% confidence intervals are shown in square parentheses for effect size and percentage change statistics. PHQ-8; Patient Health Questionnaire 8-item. GAD-7; Generalised Anxiety Disorder 7-item questionnaire. CST refers to cognitive-behavioral skills training and SRT refers to the coping self-reflection training. ${ }^{\text {a }}$ The percentage change from baseline statistics are estimates of relative change derived from the GEE models conducted separately for each outcome. Baseline was initial application where available and pre-treatment where application data was not available. 
Table 3: Reliable change index

\begin{tabular}{lcccccc}
\hline \multicolumn{1}{c}{ Outcome } & Group & Mean (LCI, UCI) & Group & Mean(LCI, UCI) & $p$-value & Wald Chi-Square \\
\hline Anxiety (GAD-7) improvement & & & & & \\
\hline RCI from baseline to initial follow-up & SRT & $2 \%(1 \%, 7 \%)$ & CST & $4 \%(2 \%, 11 \%)$ & 0.43 & 0.62 \\
RCI from baseline to longer-term follow-up & SRT & $9 \%(5 \%, 15 \%)$ & CST & $7 \%(3 \%, 14 \%)$ & 0.53 & 0.39 \\
RCI from initial to longer-term follow-up & SRT & $20 \%(14 \%, 28 \%)$ & CST & $17 \%(11 \%, 27 \%)$ & 0.63 & 0.24 \\
\hline Depression (PHQ-8) improvement & & & & & \\
\hline RCI from baseline to initial follow-up & SRT & $5 \%(2 \%, 10 \%)$ & CST & $4 \%(2 \%, 11 \%)$ & 0.86 & 0.03 \\
RCI from baseline to longer-term follow-up & SRT & $4 \%(2 \%, 9 \%)$ & CST & $4 \%(2 \%, 11 \%)$ & 0.92 & 0.01 \\
RCI from initial to longer-term follow-up & SRT & $19 \%(13 \%, 26 \%)$ & CST & $8 \%(4 \%, 15 \%)$ & 0.03 & 4.97 \\
\hline Anxiety (GAD-7) deterioration & & & & & 0.35 \\
\hline RCI from baseline to initial follow-up & SRT & $25 \%(18 \%, 34 \%)$ & CST & $22 \%(14 \%, 31 \%)$ & 0.55494 & 13.85 \\
RCI from baseline to longer-term follow-up & SRT & $11 \%(6 \%, 17 \%)$ & CST & $32 \%(23 \%, 42 \%)$ & $<0.01$ & 5.95 \\
RCI from initial to longer-term follow-up & SRT & $8 \%(4 \%, 14 \%)$ & CST & $20 \%(13 \%, 29 \%)$ & 0.01 & \\
\hline Depression (PHQ-8) deterioration & & & & & & \\
\hline RCI from baseline to initial follow-up & SRT & $30 \%(22 \%, 39 \%)$ & CST & $18 \%(12 \%, 28 \%)$ & 0.06 & 3.55 \\
RCI from baseline to longer-term follow-up. & SRT & $34 \%(26 \%, 42 \%)$ & CST & $40 \%(31 \%, 51 \%)$ & 0.30 & 1.04 \\
RCI from initial to longer-term follow-up. & SRT & $17 \%(11 \%, 25 \%)$ & CST & $30 \%(21 \%, 40 \%)$ & 0.03 & 5.01 \\
\hline
\end{tabular}




\section{Supplementary materials}

Table S1: Questions used in the workbooks to encourage the five critical reflective practices and relationship to behaviour change techniques as identified by Michie, et al., (2013).

\section{Reflection construct}

1) Awareness of one's emotional, physical, behavioural and cognitive coping responses to stressor events

2) Awareness of values and value-based goals in relation to the situation

3) Awareness of strategies applied to deal with the situation

4) Evaluation of coping strategy effectiveness in relation to values and goals

\section{Reflective question}

- Describe one of the more difficult events that you have experienced during the previous week. In your response consider: what you were thinking; how you behaved; how you felt physically and emotionally; or how your emotions, thinking, and physical feelings changed or influenced you

- When envisioning yourself coping under pressure what are some of the characteristics or behaviours that you would like to have? NOTE: These are characteristics you aspire to, not necessarily ones that you already demonstrate.

- What did you do to minimise the stress or maximise your performance in response to this event?

- What were you trying to achieve during this situation? This could be something related to a

\section{Behaviour change technique}

Feedback and monitoring: Self-monitoring of behaviour (initial reactions including emotions, thoughts and physical responses)

Identity: Valued self-identity and identity associated with changed behaviour

Feedback and monitoring: Self-monitoring of behaviour (coping strategies)

Goals and planning: Discrepancy between current behaviour and goal or capability 
goal within the activity, something personal

(e.g., improve my ability to maintain focus under pressure)

- To what degree were these strategies effective in allowing you to achieve your desired outcomes? Rated on a 7-point scale: 1 (Not at all) to 7 (Completely)

- If you circled a number greater than 1 in Q5, why do you think your strategy was effective?

- If you circled a number less than 7 in Q5, why do you think your strategy was not completely effective?

5) Adaptation of strategies to promote improvements in future coping
- What useful Knowledge, Skills or Abilities (KSAs) could be gained or developed from this experience?

- How would you change or improve your strategy in the future to help you cope better when dealing with a similar challenge, or situation?
Identity: Reframing

\section{Goals and planning:}

Goal setting (behaviour). 
49 RUNNING HEADER: STRENGTHENING RESILIENCE IN OFFICER CADETS

Table S2: Means differences, confidence intervals and power for the primary and secondary outcomes.

\begin{tabular}{|c|c|c|c|c|c|c|}
\hline & \multicolumn{3}{|c|}{ Initial follow-up } & \multicolumn{3}{|c|}{ Longer-term follow-up } \\
\hline & $\begin{array}{c}\text { Mean Differences (SRT } \\
\text { vs. CST ) }\end{array}$ & $\begin{array}{c}\text { Margin at } \\
\text { SRT 80\% } \\
\text { effective }\end{array}$ & $\begin{array}{l}\text { Non-inferiority } \\
\text { conclusion }\end{array}$ & $\begin{array}{c}\text { Mean Differences (SRT } \\
\text { vs. CST) }\end{array}$ & $\begin{array}{c}\text { Margin at SRT } \\
80 \% \text { effective }\end{array}$ & $\begin{array}{l}\text { Non-inferiority } \\
\text { conclusion }\end{array}$ \\
\hline \multicolumn{7}{|c|}{ PRIMARY OUTCOMES } \\
\hline \multicolumn{7}{|c|}{ Anxiety (GAD-7) } \\
\hline SRT vs CST & $-1.03[-2.31,0.25]$ & 0.62 & Equivalence & $-2.92[-4.2,-1.64]$ & 0.70 & superiority \\
\hline \multicolumn{7}{|c|}{ Depression (PHQ-8) } \\
\hline SRT vs CST & $0.01[-1.23,1.25]$ & 0.45 & Equivalence & $-2.35[-3.64,-1.07]$ & 1.02 & superiority \\
\hline \multicolumn{7}{|c|}{$\begin{array}{l}\text { Perceived stressor } \\
\text { frequency }\end{array}$} \\
\hline SRT vs CST & $-11.05[-15.64,-6.47]$ & 6.67 & Equivalence & $-8.87[-14.62,-3.13]$ & 1.83 & superiority \\
\hline
\end{tabular}

PHQ-8; Patient Health Questionnaire 8-item. GAD-7; Generalised Anxiety Disorder 7-item questionnaire. CST refers to cognitive-behavioral skills training and SRT refers to the coping self-reflection training. 


\section{Figures}

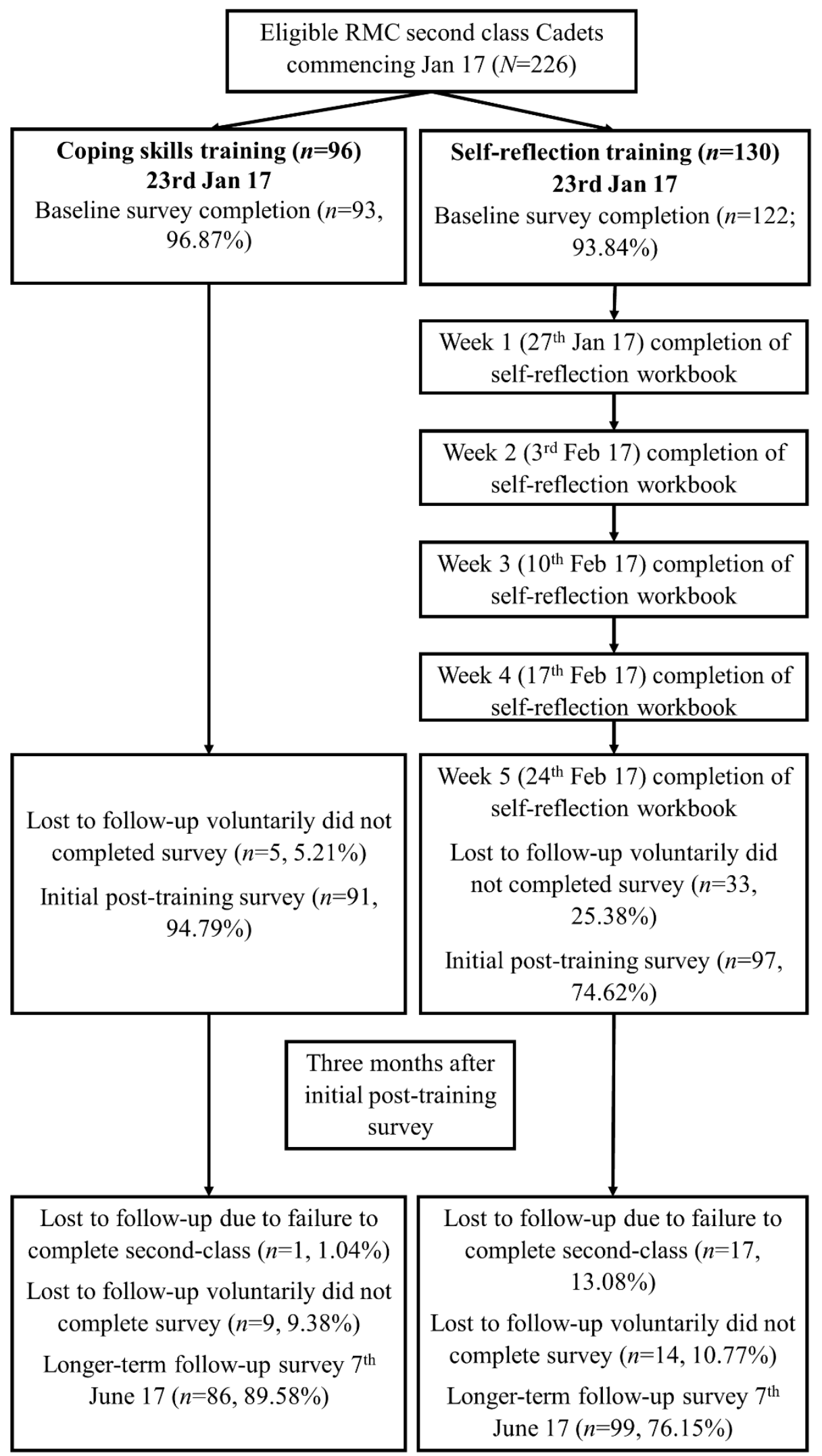

Figure 1: CONSORT flow diagram for SRT and CST programs and data collection 


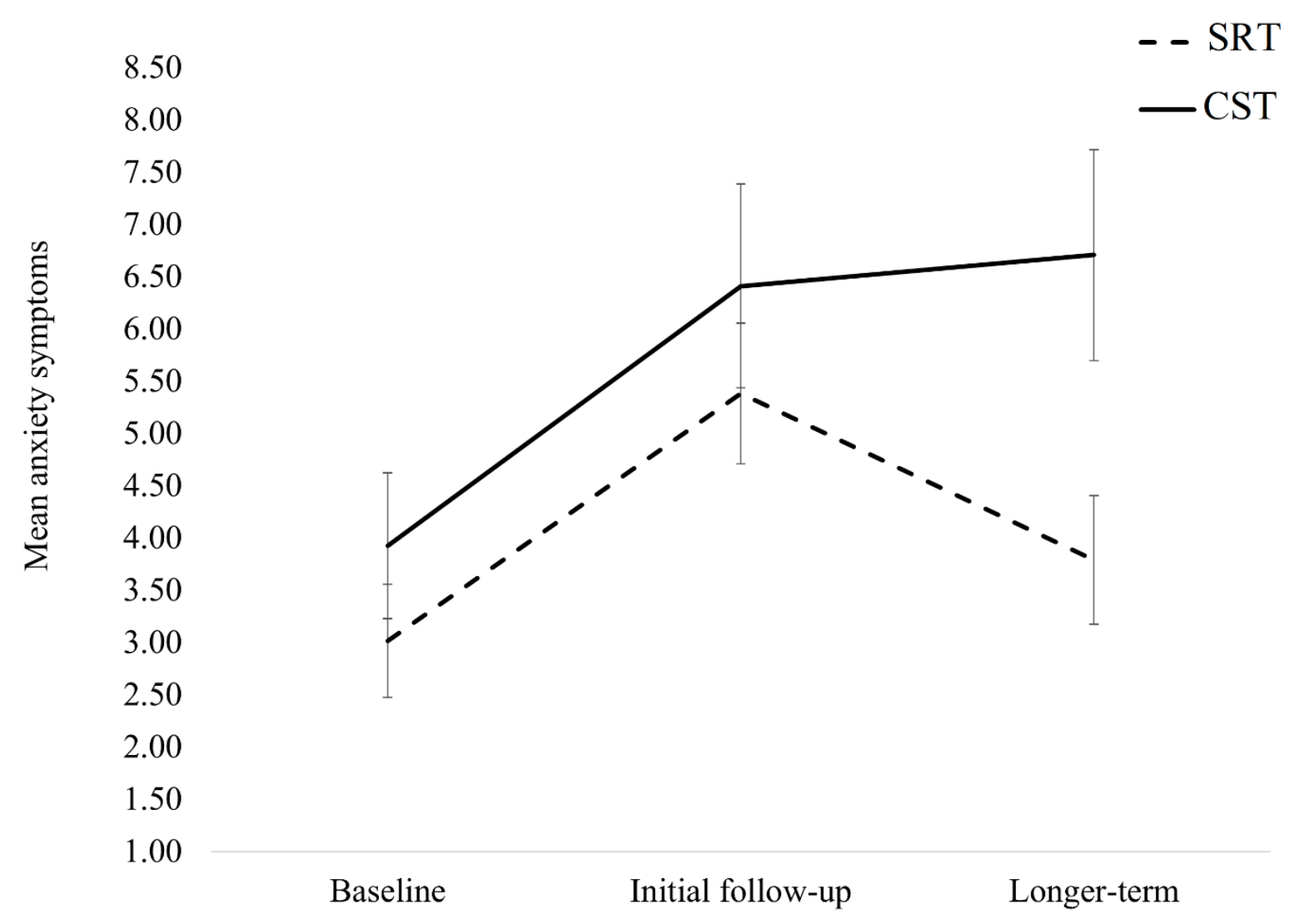

Figure 2: Mean summary baseline, initial and longer-term follow-up scores for anxiety symptoms for SRT and CST resilience programs. 


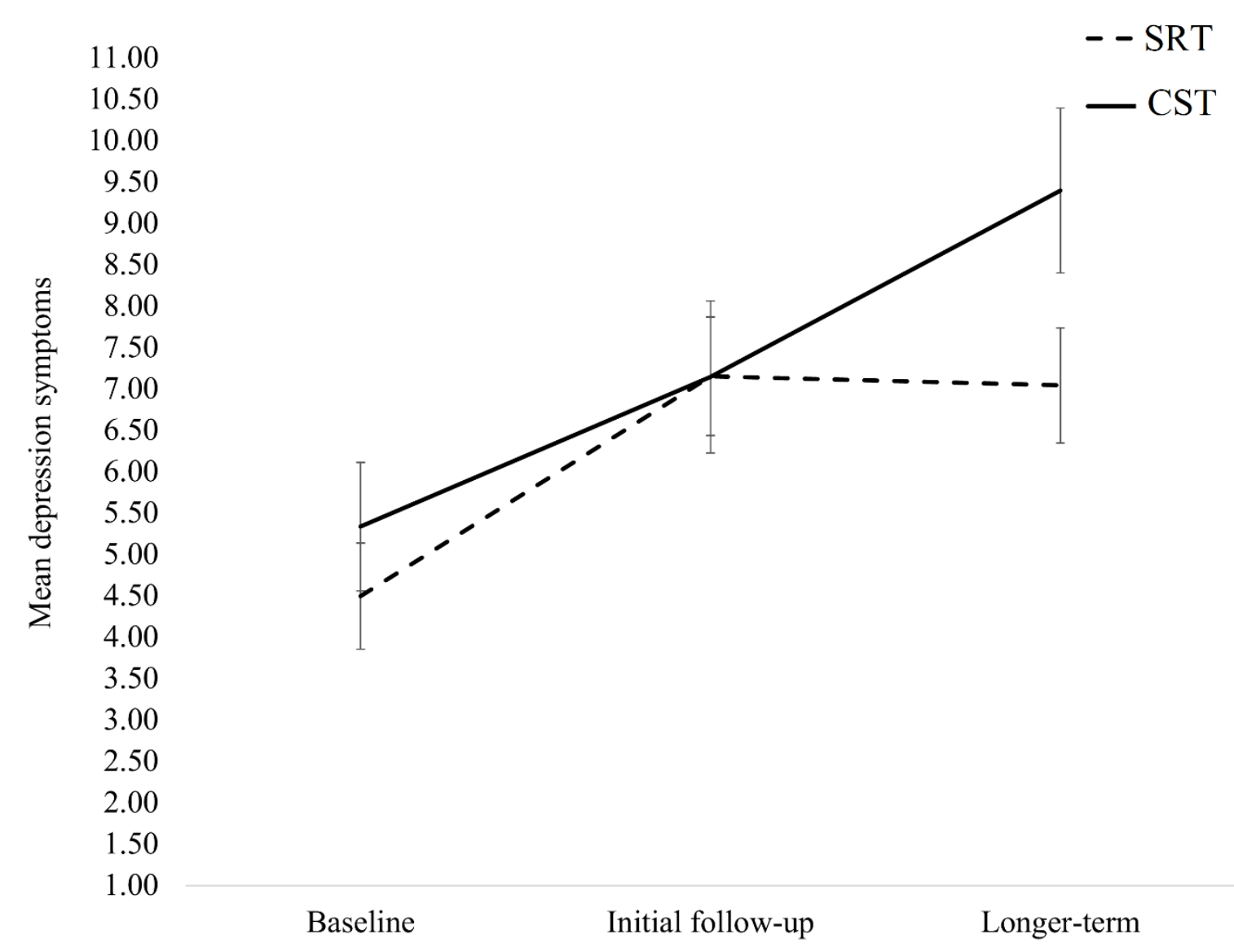

Figure 3: Mean summary baseline, initial and longer-term follow-up scores for depression symptoms for SRT and CST resilience programs. 


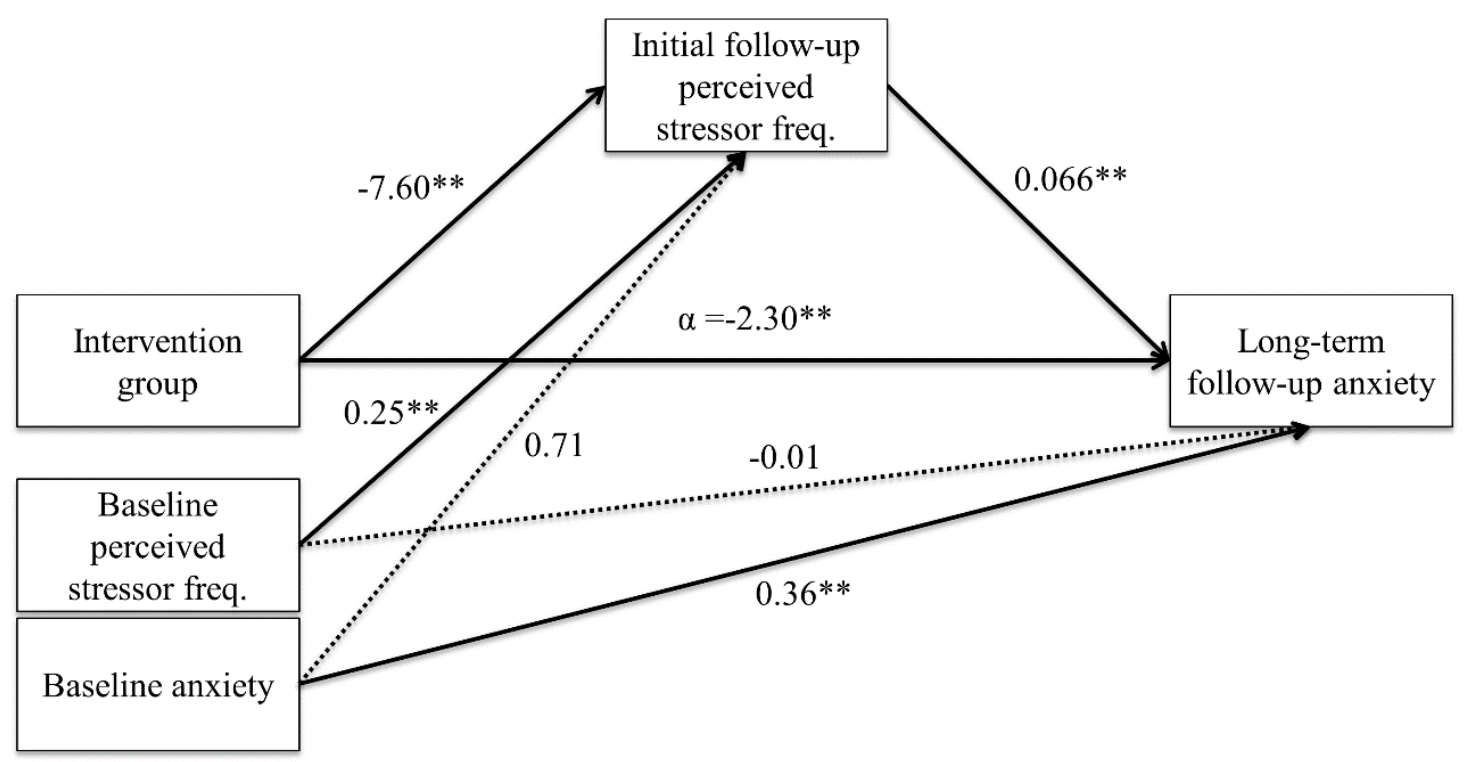

Figure S1: Mediation model with initial follow-up perceived stressor frequency as the mediator in the relationship between intervention and long-term follow-up anxiety symptoms. Note: Values represent unstandardised coefficients. ${ }^{*} p<.05 ;{ }^{* *} p<.01$ (twotailed ); $\alpha$ values are direct effects.

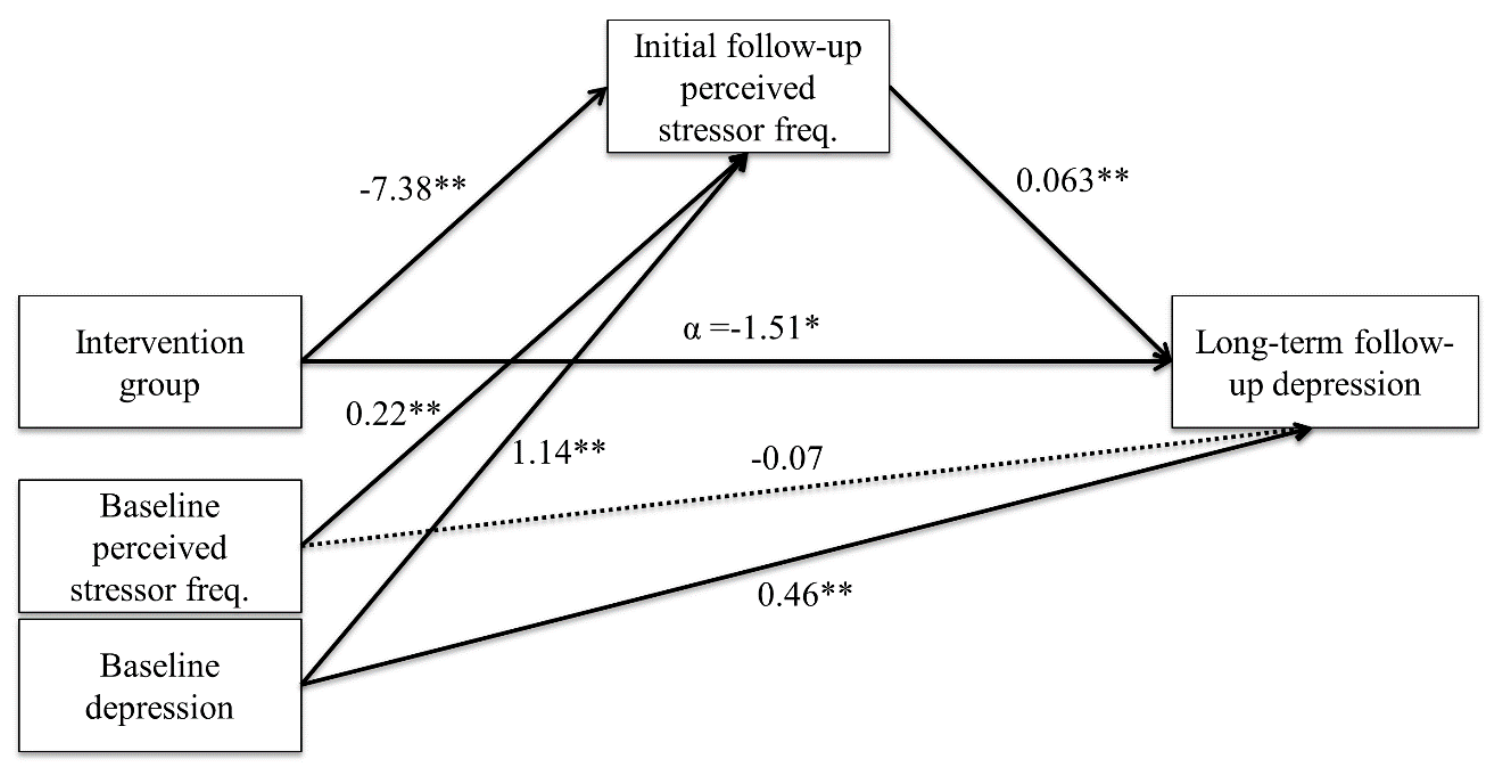

Figure S2: Mediation model with initial follow-up perceived stressor frequency as the mediator in the relationship between intervention and long-term follow-up depression symptoms. Note: Values represent unstandardised coefficients. ${ }^{*} p<.05 ; * * p<.01$ (twotailed ); $\alpha$ values are direct effects. 